\title{
Influencia de lenguas indígenas en el registro festivo del diario chileno La Cuarta
}

\author{
Abelardo San Martín Núñez* \\ Universidad de Chile
}

\begin{abstract}
Resumen
El propósito del presente estudio es establecer, cuantitativa y cualitativamente, el carácter que asume la presencia de las lenguas indígenas en el léxico empleado en el registro festivo del diario chileno La Cuarta. Para tal propósito se relevaron las unidades léxicas de esa procedencia empleadas con intencionalidad festiva en un corpus de 375 páginas del mencionado periódico. Las voces y locuciones así recopiladas se analizaron desde dos puntos de vista: vitalidad relativa (medida respecto de su frecuencia de empleo, su capacidad para originar familias léxicas y para establecer relaciones de sinonimia al interior del corpus) y origen etimológico (atendiendo también a los recursos neológicos implicados en su empleo). Como resultado se identificaron y procesaron 132 lexías correspondientes a nuestra definición de neologismo estilístico de base indígena. La última sección del artículo consiste en un inventario lexicográfico de los indigenismos recopilados y sus derivados.
\end{abstract}

Palabras clave: indigenismos en el español de Chile, préstamo léxico, lenguas en contacto.

* Para correspondencia dirigirse a: Abelardo San Martín Núñez (asmartin@uchile.cl), Departamento de Lingüística, Facultad de Filosofía y Humanidades, Universidad de Chile, Ignacio Carrera Pinto 1025, Tercer Piso, Ñunoa, Santiago, Chile. 


\title{
THE INDIGENOUS LANGUAGES INFLUENCE IN FESTIVE REGISTER OF THE ChILEAN NEWSPAPER LA CUARTA
}

\begin{abstract}
The aim of this study is to determine, qualitatively and quantitatively, the nature and extent of lexical borrowing from indigenous languages, as reflected in a representative sample of a festive register Chilean newspaper, La Cuarta. For this purpose, lexical items from that origin employed with festive intentionality in a corpus of 375 pages of that newspaper were gathered. These lexical items were used to assess the relative vitality of words of Indian origin documented in the corpus (measured by their frequency of occurrence, their capacity to originate derivatives in the host language, their capacity to originate lexical families, and their value in the semantic fields that they share with synonymous indigenous borrowings documented in the corpus) and etymological origin (in this respect, the lexicogenetic process undergone by indigenous borrowings to convey their festive connotations). As a result, 132 lexical items of that origin and their derivatives were documented in the corpus. The last section of the article consists of a lexicographic inventory of the Indian loanwords documented and their Spanish derivatives.
\end{abstract}

Key words: indian loanwords in Chilean Spanish, lexical borrowing, languages in contact.

Recibido: 30/08/09. Aceptado: 02/11/09.

\section{INTRODUCCIÓN}

\section{1. NATURALeZa, objetivos y alCANCE Del estudio}

El presente estudio aborda, de manera particular y en detalle, uno de los aspectos considerados en una investigación más amplia que, en los últimos años, hemos venido realizando en torno a los recursos de creación léxica de naturaleza expresiva en el diario chileno de carácter popular La Cuarta. Como ya hemos insistido en otro lugar, el diario La Cuarta pretende acercarse al lenguaje coloquial en su variante más familiar, incluyendo unidades léxicas de carácter jergal juvenil y delictivo. Prácticamente la totalidad de los hechos 
noticiosos y de los subgéneros periodísticos son reformulados en un lenguaje coloquial y en un registro festivo. Esta característica está determinada por el perfil, divulgado por el mismo cotidiano, que lo describe como "el diario popular", es decir, como un periódico dirigido a un amplio sector de la población, en especial, aquel perteneciente a los estratos medio-bajo y bajo de la sociedad chilena (San Martín 2000-2001: 217 y 218).

En este trabajo se estudia el carácter que asume la influencia de las lenguas indígenas en el registro festivo del diario chileno La Cuarta. Para tal cometido, nos hemos propuesto determinar la participación de dichas lenguas en los procesos de cambio semántico, formación léxica y fijación fraseológica, implicados en las voces y locuciones de motivación festiva relevadas en una muestra de quince ejemplares del mencionado periódico. Asimismo, dichas voces y locuciones, con su caracterización gramatical, variantes y ejemplos de uso correspondientes, se han documentado en un inventario lexicográfico.

Nuestro concepto de neologismo estilístico de base indígena se restringe a aquellas unidades léxicas (voces o locuciones) que: 1) son utilizadas con intencionalidad festiva; 2) no aparecen recogidas en el DRAE, aparecen marcadas en dicho repertorio con una acepción diferente o como americanismos o chilenismos y, por supuesto, 3) tienen un origen etimológico indígena o manifiestan la influencia de alguna lengua indígena.

\section{MARCO CONCEPTUAL}

Nuestro trabajo se inscribe dentro del amplio ámbito de la lexicología, más precisamente, en el de la neología estilística. Tal como señalamos en un trabajo anterior (San Martín 2000-2001: 213), diferenciamos la neología estilística, que está al servicio del afán expresivo del hablante (escritor o periodista), de la neología referencial, que se orienta a satisfacer las necesidades designativas de las nuevas realidades que pasan a incorporarse al mundo referencial de una lengua. Con respecto a los medios de los que dispone la lengua para renovar el léxico, Guiraud (1965: 36) reconoce a lo menos cuatro recursos generales: las onomatopeyas, los préstamos, la formación morfológica y el cambio semántico.

Dentro de este marco general, en el presente estudio nos ocupamos del recurso de innovación léxica reconocido universalmente bajo el concepto de "préstamo léxico". Los préstamos son palabras provenientes de otras 
lenguas y su difusión depende de diferentes factores (políticos, económicos, culturales, etc.). El préstamo como fenómeno lingüístico-cultural se inserta dentro del problema del contacto entre diferentes lenguas y culturas ${ }^{1}$. Por otro lado, debido a la naturaleza estilística de nuestro estudio, hemos prestado especial atención a la coocurrencia de otros procedimientos de creación léxica implicados en los casos de préstamos de lenguas indígenas analizados, primordialmente, a la incidencia de cambios semánticos, formación de derivados o fijación fraseológica.

\section{1. EL ESTUDIO DE LA INFLUENCIA DE LAS LENGUAS INDÍGENAS EN EL LÉXICO DEL ESPAÑOL HABLADO EN CHILE}

Entre las descripciones del español de Chile de carácter global, destaca la realizada por Rabanales (1953) desde un punto de vista diferencial y con abundante ejemplificación ${ }^{2}$. Tanto por lo que refiere a los chilenismos lexicogenésicos como a los semasiológicos, el autor distingue entre los de base española como no española (indígena o extranjera). Posteriormente, Rabanales (1958) se propone mostrar algunos de los recursos lingüísticos de expresión de la afectividad del español, sobre todo, los típicos del habla familiar y vulgar en Chile ${ }^{3}$. El autor los clasifica, según su rasgo preponderante, en recursos fonéticos, morfológicos, sintácticos y léxicos, incluyendo también un número considerable de voces de origen indígena. Por otro lado, de especial interés resultó la consulta de Oroz (1966), completísima descripción de las particularidades del español contemporáneo en todos los niveles y regiones de nuestro país. En el prólogo, el autor destaca la importancia de los medios de comunicación (prensa, radiodifusión, cine) como factores de diferenciación dialectal:

La prensa diaria constituye hoy por hoy, uno de los instrumentos más poderosos y responsables de transmisión de la lengua escrita, como es la radiodifusión respecto de la lengua oral. Y su influencia lingüística es

1 El problema de las lenguas en contacto, cuya existencia ha sido permanente en la historia de la humanidad, puesto que la condición de contacto entre los pueblos es la normal y la de aislamiento una excepción, se desarrolla en Rotaexte (1990) y Lastra (1992).

2 Rabanales (1953) adopta un criterio de origen homogeográfico, entendiendo por chilenismo toda expresión originada en Chile desde cualquier punto de vista gramatical: morfológico, lexicogenésico, sintáctico, fonético, ortográfico, semasiológico y estilístico (p. 39).

3 Los recursos expresivos del español chileno se estudian también en Oroz (1937-1938). 
decisiva, siendo para la gran masa de la población la única o la principal fuente de información cultural (1966: 8).

Luego de la Introducción, en la que se refiere a algunos aspectos históricodialectales de la formación y estado actual del español americano y chileno, el material lingüístico reunido se ordena de acuerdo con los diferentes niveles de análisis: fonética, morfología, sintaxis y vocabulario. En lo que se refiere al vocabulario, Oroz destaca que, debido a su propia naturaleza, la diferenciación del español americano se concentra, principalmente, en innovaciones de tipo léxico más que fonéticas y gramaticales:

El rasgo más distintivo de las hablas sudamericanas no reside tanto en las particularidades fonéticas y gramaticales como en las de su léxico. Gracias a la amplitud y flexibilidad del sistema, la lengua está en condición de renovar constantemente su vocabulario según las preferencias mentales y las necesidades expresivas de los hablantes (1966: 404).

El autor señala que existen tres elementos fundamentales que confluyen en la formación del léxico hispanoamericano, en general, y chileno, en particular: el elemento español, el indígena y el extranjero. El elemento indígena, que es el que aquí nos interesa, se ha incorporado, según este autor, principalmente, mediante la influencia del quechua y el mapuche, incluso, más allá de las necesidades denominativas que la nueva realidad americana impuso a los conquistadores europeos. Según Oroz (1966: 405):

Aun prescindiendo de los nombres geográficos, usamos corrientemente en el habla cotidiana un gran número de palabras de origen indígena. Algunas se emplean en todo el continente de habla española (americanismos), otras son de uso exclusivo de nuestro país y un tercer grupo no tiene sino el carácter de provincionalismos.

Luego señala una serie de indigenismos de uso general en Chile de origen quechua relativas a objetos, vida social, cultura, comidas, vida agrícola, fauna y flora, entre otros ámbitos. Asimismo, para la influencia del mapuche indica voces relacionadas con instituciones sociales, oficios, costumbres y partes del cuerpo.

Para efectos de nuestro estudio, ha sido importantísima la consulta de tres fuentes primarias. En primer lugar, el Diccionario etimológico de las voces chilenas derivadas de lenguas indígenas americanas de Rodolfo Lenz (1905-1910), monumental obra de consulta obligada para los estudios indigenistas tanto en Chile como en Hispanoamérica. Por otro lado, los trabajos de Prieto (1979) sobre los indigenismos, en general, y (2006) sobre los quechuismos, en particular, en la prensa de Santiago de Chile, 
que no solo han constituido una valiosa fuente de consulta léxica, sino que -además- un modelo metodológico para la indagación de la influencia de las lenguas indígenas en el léxico festivo de La Cuarta.

\section{METODOLOGÍA}

\section{1. ESQUEMA OPERATIVO}

El esquema operativo del presente estudio comprendió las siguientes etapas:

3. 1. 1. Relevamiento de los neologismos estilísticos de origen indígena registrados en el corpus

A partir de la lectura de los ejemplares que conforman el corpus de nuestro estudio, se identificaron las creaciones léxicas uni y pluriverbales que satisficieran los siguientes criterios: aparecer en contextos festivos estilísticamente marcados; ostentar el estatuto de neologismos, de acuerdo con el criterio de constrastividad empleado, es decir, no estar registrado -formal o semánticamente- en el Diccionario académico o figurar como americanismo o chilenismo; y estar relacionado su origen con alguna lengua indígena, ya sea por simple adopción de un préstamo o por alguna otra influencia.

3. 1. 2. Fichaje de cada uno de los neologismos estilísticos de origen indigena recopilados

Una vez localizado, cada indigenismo se fichó de acuerdo con la siguiente pauta: origen etimológico, clasificación gramatical, acepciones con sus respectivos contextos de uso debidamente localizados, variantes gráficas y morfológicas, ámbito de uso, nivel sociocultural, nivel estilístico, derivados, sinónimos y variantes, frecuencia de aparición en el corpus, contrastes formales (gráficos o morfológicos) o semánticos (acepciones) con el Diccionario académico y, por último, inclusión en el Diccionario académico. 
3. 1. 3. Elaboración de un inventario lexicográfico de los neologismos de base indigena del corpus

Con la información recopilada en las etapas anteriores se confeccionó un inventario lexicográfico de los diferentes neologismos del corpus, con indicación etimológica, descripción gramatical, definición y observaciones acerca de su origen.

3. 1. 4. Clasificación de los diversos neologismos estilísticos de base indígena relevados en el corpus

Basándonos en la información etimológica disponible, se procedió a clasificar los neologismos del corpus de acuerdo con su origen indígena. Respecto de cada categoría, además, se hicieron observaciones acerca de la manera cómo operaban los diferentes procedimientos de creación léxica concurrentes con el préstamo indígena con su correspondiente ejemplificación.

\section{1. 5. Procesamiento del inventario de neologismos estilísticos de base indigena}

Teniendo en cuenta la frecuencia de aparición de cada neologismo, se determinó su vitalidad según su distribución y rango, su predisposición para formar familias léxicas y para establecer relaciones de sinonimia, así como otros tipos de vínculos formales o semánticos entre lexías univerbales y pluriverbales.

\section{2. CORPUS}

El corpus en el que se basó el estudio estuvo constituido por 15 ejemplares del diario La Cuarta, distribuidos de la siguiente manera: 10 ejemplares aparecidos entre noviembre y diciembre del año 1998 y cinco diarios aparecidos entre mayo y junio de 2004. Tal número de ejemplares totaliza aproximadamente 375 páginas, las que fueron exhaustivamente revisadas, sin exclusión de ninguna de las diversas secciones del periódico. 


\section{PRESENTACIÓN Y ANÁLISIS DE LOS RESULTADOS}

\section{1.VITALIDAD}

En la determinación de la vitalidad relativa de los neologismos estilísticos de origen indígena relevados se han considerado los siguientes criterios: frecuencia de aparición en el corpus, productividad (medida por la capacidad para formar familias léxicas) y sinonimia (predisposición para establecer relaciones de similitud semántica) al interior del repertorio. A continuación, se analizan los resultados obtenidos tras la aplicación sucesiva de cada uno de los mencionados parámetros.

\section{1. 1. Frecuencia de aparición en el corpus}

En nuestro corpus se documentó un repertorio de 132 neologismos estilísticos de base indígena que registraron 530 ocurrencias en total. En el cuadro siguiente presentamos los índices de frecuencia y los respectivos rangos de aparición de los diferentes neologismos de nuestro corpus.

Cuadro 1a. Distribución de lexías según frecuencia y rango (Frecuencia: 17 a 2 )

\begin{tabular}{clc}
\hline Rango & Lexía & Frecuencia \\
\hline 1 & Chilito & 49 \\
2 & cototo, ta & 38 \\
3 & pirulo, la & 32 \\
4 & che & 25 \\
4 & papa & 25 \\
5 & chilensis & 24 \\
6 & condoro & 17 \\
7 & cahuín & 15 \\
8 & cototudo, da & 14 \\
8 & Jaguarlandia & 14 \\
9 & cuate & 13 \\
10 & chuncho & 9 \\
10 & guatón & 9 \\
11 & choreado, da & 8
\end{tabular}




\begin{tabular}{|c|c|}
\hline 11 & guata \\
\hline 12 & tatita \\
\hline 13 & mate \\
\hline 14 & guagua \\
\hline 14 & poroto, ta \\
\hline 14 & tata \\
\hline 15 & achuntar \\
\hline 15 & caturro \\
\hline 15 & cuico \\
\hline 15 & charchazo \\
\hline 15 & charqui, ojo al \\
\hline 15 & choro, ra \\
\hline 15 & matearse \\
\hline 15 & pilcha \\
\hline 15 & poto \\
\hline 15 & pololo, la \\
\hline 15 & sohua \\
\hline 15 & taita \\
\hline 16 & callulla \\
\hline 16 & combo \\
\hline 16 & copuchento, ta \\
\hline 16 & chilenitas, hacer \\
\hline 16 & chuchoca \\
\hline 16 & descharchetar \\
\hline 16 & guacho \\
\hline 16 & guagüita \\
\hline 16 & guaracazo \\
\hline 16 & guatita \\
\hline 16 & jaguar \\
\hline 16 & papa, agarrar \\
\hline 16 & papaya \\
\hline 16 & patuleca \\
\hline 16 & pitearse \\
\hline 16 & pucho \\
\hline 16 & tuna, como \\
\hline
\end{tabular}




$\begin{array}{lll}16 & \text { tunazo } & 3 \\ 17 & \text { cancha, rayar la } & 2 \\ 17 & \text { cateo de la laucha, al } & 2 \\ 17 & \text { concho, a } & 2 \\ 17 & \text { condorearse } & 2 \\ 17 & \text { copucha } & 2 \\ 17 & \text { chascón } & 2 \\ 17 & \text { cholito, ta } & 2 \\ 17 & \text { choriflai } & 2 \\ 17 & \text { huinchas, estar que corta las } & 2 \\ 17 & \text { mateíto, ta } & 2 \\ 17 & \text { mateo, tea } & 2 \\ 17 & \text { mote, cachar el } & 2 \\ 17 & \text { papa misma } & 2 \\ 17 & \text { peñi } & 2 \\ 17 & \text { pichanga } & 2 \\ 17 & \text { pichangosa } & 2 \\ 17 & \text { porotos, ganarse los } & 2 \\ 17 & \text { puchito } & 2\end{array}$

Cuadro 1b. Distribución de lexías según frecuencia y rango (frecuencia 1)

Frecuencia: 1

\section{Lexías}

ajaguarado (da), año del ñauca (del), cachaña (hacer una), cahuinear, cahuinero (ra), caracha, carpa (levantar), catete, catetear, catetemente, condorazo, copuchenta, coquero (ra), cototo, curagüilla, chacra, chacriento, chapulín, charchita, chasquilla (maestro), chingar, chirimoyo, choclero, chocolito (ta), chorearse, choreza, chorísimo, chucho, chupalla, guata (jurar de), guata (asegurar de), guata (como patá en la), guatepán, guatero con uñas, guaterito con uñas, guatita (jurar de), guatear, jaguarito (ta), luma, macanudo, malacatoso, mano con tiza, moai, nana, ojota (mostrar la), pampear, papita pal loro, papa (soltar la), papa (rayar la)*, paquita, patuleco (ca), pichangeo, pilchita, pilucho (cha), pino (hacer el), pirulín, pololear, porotazo, pucho lacio, quique (hecho un), quisca, ruca, sohuita, tongua.

* Grafía registrada en el diario; variaciòn de rallar la papa. 


\section{1. 2. Productividad}

El concepto de productividad que aquí aplicamos es el empleado por Prieto en diferentes trabajos relativos al préstamo léxico (1979, 1992, 1993-1994), definido como "la capacidad de los préstamos para relacionarse sincrónicamente (tanto desde el punto de vista fonológico como semántico) con las voces con las que comparten el mismo lexema de base" (19931994: 301). En el presente análisis hemos ampliado levemente el alcance de dicha noción, de modo de incluir formas que, si bien no comparten el mismo radical, establecen vínculos de similitud formal, específicamente, mediante paronomasia. Las lexías relacionadas de esta manera constituyen una familia léxica y su tamaño será considerado aquí como un índice de la vitalidad relativa de cada neologismo.

De acuerdo con el número de sus miembros, las familias léxicas registradas en nuestro corpus pueden clasificarse del siguiente modo:

1. Familia léxica de seis miembros:

choro, chorísimo, choreado, chorearse, choreza, choriflai guata, guatita, guatón, guatear, tongua, guatepán

2. Familia léxica de cuatro miembros:

jaguar, jaguarito, ajaguarado, Jaguarlandia

mate, mateo, mateíto, matearse

charcha, charchazo, chachita, descharchetar

3. Familia léxica de tres miembros:

cahuín, cahuinear, cahuinero

catete, catetear, catetemente

pichanga, pichangosa, pichangeo

copucha, copuchento(ta), copuchenta

cototo, cototo(a), cototudo

4. Familia léxica de dos miembros:

papa, papaya

pilcha, pilchita

condoro, condorearse

pirulo, pirulín

pololo, pololear

poroto, porotazo 
chacra, chacriento

pucho, puchito

sohua, sohuita

Chilito, chilensis

tata, tatita

guagua, guagüita

Con el propósito de complementar nuestro análisis de la productividad de los neologismos de base indígena del corpus, hemos considerado otros criterios indicadores de la misma, como la ocurrencia de lexías univerbales en pluriverbales.

Ocurrencia de lexías univerbales en pluriverbales

\begin{tabular}{|c|c|c|}
\hline papa & en & $\begin{array}{l}\text { papa misma } \\
\text { agarrar papa } \\
\text { soltar la papa } \\
\text { rayar la papa } \\
\text { jurar de guata } \\
\text { asegurar de guata } \\
\text { como patá en la guata }\end{array}$ \\
\hline papita & en & papita pal loro \\
\hline poroto & en & ganarse los porotos \\
\hline ñauca & en & del año del ñauca \\
\hline mote & en & cachar el mote \\
\hline cachaña & en & hacer una cachaña \\
\hline carpa & en & levantar carpa \\
\hline laucha & en & al cateo de la laucha \\
\hline concho & en & a concho \\
\hline chilenitas & en & hacer chilenitas \\
\hline guatero & en & guatero con uñas \\
\hline guaterito & en & guaterito con uñas \\
\hline huincha & en & estar que corta las huinchas \\
\hline tiza & en & mano con tiza \\
\hline ojota & en & mostrar la ojota \\
\hline pino & en & hacer el pino \\
\hline quique & en & hecho un quique \\
\hline tuna & en & como tuna \\
\hline
\end{tabular}




\section{1. 3. Sinonimia}

En nuestro análisis de la vitalidad de los neologismos, como ya se señaló, hemos considerado la predisposición de los mismos para establecer relaciones de identidad o cercanía semántica entre sí, al interior del repertorio. La importancia de reconocer este aspecto radica en que una de las motivaciones de la creación léxica en las publicaciones periodísticas es la necesidad de contar con un repertorio más amplio de unidades léxicas conmutables, de manera de evitar repeticiones innecesarias. Desde un punto de vista más general, dicha necesidad se relaciona con el concepto de correferencialidad textual, definida como la relación entre elementos lingüísticos que comparten un mismo referente. En La Cuarta como recurso de correferencialidad no solo se utilizan formas convencionales del discurso periodístico, sino que con mayor frecuencia, neologismos estilísticamente marcados como los que conforman nuestro corpus (cf. San Martín 2000-2001).

Las lexías relacionadas por sinonimia constituyen grupos de sinónimos y su tamaño es considerado aquí como indicador de la vitalidad de los neologismos, teniendo en cuenta los conjuntos de tres sinónimos o más, e incluyendo también sus derivados y variantes, a fin de tener una visión más amplia de la sinonimia. Según el número de miembros, los grupos de sinónimos registrados en nuestro corpus se han clasificado como sigue:

1. Grupos de tres sinónimos cototudo, macanudo, cototo 'estupendo'

2. Grupos de dos sinónimos combo, charchazo 'puñetazo' copucha, cahuín 'chisme' chapulín, poroto 'niño' cahuinero, copuchento 'chismoso' al cateo de la laucha, ojo al charqui 'atento, alerta, a la espera'

\section{2. Clasificación de los indigenismos léXicos de NATURALEZA ESTILÍSTICA EN EL REGISTRO FESTIVO DE LA CUARTA}

Dentro de los recursos de creación léxica en el registro festivo del diario La Cuarta, la influencia de las lenguas indígenas es importante y se presentó, como ya indicamos, con una productividad de 132 casos en total. Debido a la naturaleza estilística de nuestro corpus, en la mayoría de ellos es interesante considerar el cambio semántico que se produce respecto de su 
acepción nominativa, estilísticamente no marcada. Para una identificación más detallada de la etimología y sentido primigenio de estas voces, remitimos a la entrada correspondiente del inventario lexicográfico. En nuestra muestra detectamos la presencia de voces de origen quechua, mapuche, azteca, guaraní, aimara, rapanui, así como otras de difícil determinación. En conjunto, prevalecen las palabras del quechua y el mapuche, en especial las primeras, por sobre las de otro origen.

\section{2. 1. Quechua}

En relación con el quechua, identificamos 60 unidades léxicas. Algunas de estas lexías no manifiestan un cambio semántico notable desde su étimo original: guagua 'bebé', chingar 'frustrar', nana 'herida, 'dolencia física', tincar 'intuir', tincada 'presentimiento' y taita 'padre'. Entre las voces que manifiestan algún recurso de cambio semántico, están guacho 'desparejado' (< 'niño huérfano'), poroto 'niño', 'aporte' (< 'habichuela'), combo 'puñetazo' (< 'almadana'), chuchoca 'ajetreo' (< 'maíz cocido'), quisca 'cuchilla' (< 'espina'), tata 'anciano' ( $<$ 'padre'), papa 'verdad', 'novedad' ( $<$ 'patata'), chacra 'desorden' ( $<$ 'huerta'), caracha 'cantidad escasa' (< 'sarna'), mate 'cabeza' (< 'calabaza'), pucho 'cigarrillo' (< 'colilla', 'sobrante'), chupalla 'expresión de sorpresa' ( $<$ 'sombrero de paja') y choro 'excelente' ( $<$ 'concha', 'mejillón' por ponderación de este molusco o, tal vez, de su connotación sexual).

En cuanto a voces derivadas, se encontraron guagüita (< guagua), papita $(<$ papa), tatita $(<$ tata $)$, mateito, mateo 'estudioso' y matearse 'estudiar' ( $<$ mate), puchito (< pucho), yayita 'defecto' (< yaya 'herida'), guaracazo 'golpe', 'explosión' (< guaraca 'látigo'), macanudo 'estupendo' (<macana 'arma contundente'), choclero 'diente' (< choclo 'maíz'), condorearse 'equivocarse', condorazo 'error garrafal' y condoro 'error' ( $<$ cóndor 'ave de rapiña'), coquero 'que consume cocaína' $(<\operatorname{coca})$, pampear 'extenderse, divulgarse' (< pampa 'llanura'), choreado 'molesto' y chorearse 'molestarse' ( $<$ chorear 'refunfuñar'), achuntar 'acertar' ( $<$ chonta 'árbol del que se extraen flechas'), chacriento 'desordenado' ( $<$ chacra 'huerta'), poruñazo 'robo' (< poruña 'cucharón'), porotazo 'gran aporte' (< poroto), choreza 'acción extraordinaria', chorísimo y choriflai $(<$ choro $)$.

Por otro lado, entre las unidades fraseológicas, se testimoniaron: papa en papa misma 'solución', agarrar papa 'atreverse', soltar la papa 'decir la verdad', rayar la papa 'insistir inútilmente' y verle el ojo a la papa 'tener éxito', papita en papita pal loro 'fácil', poroto en ganarse los porotos 'ganarse el sustento', cancha en rayar la cancha 'exigir, poner reglas', ñauca en del año del ñauca 'muy viejo', charqui 'carne seca' en ojo al charqui 
'a la espera', mote 'maíz o trigo cocido' en cachar el mote 'averiguar', huincha 'cinta' en estar que corta las huinchas 'estar ansioso', chasquilla 'flequillo' en maestro chasquilla 'maestro poco profesional', choro en andar con los choros fuera del canasto 'andar muy molesto' (analogía formal de choro con choreado del quechuismo chorear 'refunfuñar'), ojota 'sandalia campesina' en mostrar la ojota 'mostrar descortesía y falta de urbanidad' y carpa 'tienda' en levantar carpa 'erectarse el miembro viril'.

\section{2. 2. Mapuche}

Respecto del mapuche consignamos 48 voces y locuciones. Sin cambio semántico importante registramos poto 'trasero'. Entre las voces mapuches registradas con cambio semántico, están: cahuín 'chisme', 'confusión' (< 'borrachera, junta para emborracharse'), guata 'millón de pesos' ( $<$ 'panza', por el premio "gordo" de la lotería), copucha 'chisme, noticia inflada' $(<$ 'vejiga'), charcha 'deficiente' ( $<$ 'papada', por connotación negativa de este pliegue cutáneo), chucho 'cárcel' ( $<$ 'lechuza'), chuncho 'relativo al Club Deportivo de la Universidad de Chile' (< 'lechuza', por ser el símbolo de dicho club), pichanga 'partido informal de fúlbol' (< 'fiesta informal'), peñi 'mapuche' (por estereotipo de esta palabra que significa 'hermano' muy usual entre los araucanos), cototo 'excelente', 'grande' (< 'hinchazón', contaminación del mapuche t'ot'o y quechua coto), pirulo 'elegante' $(<$ pirúl 'masa cilíndrica frita' del quechua piruru 'disco del huso'), catete 'cargante, molestoso' (< 'preparado de harina tostada con grasa de chancho', 'demonio'), curagüilla 'alcohólico' (por analogía fonética con curado 'ebrio'), pololo, a 'novio, a' (< pululu 'moscardón'), luma 'castigo (< ‘árbol de madera muy dura'), ruca 'sede del Club Deportivo Colo Colo' ( $<$ 'casa', obviamente, por identificarse este club con el pueblo mapuche).

Por lo que refiere a voces derivadas, encontramos charchita $(<$ charcha), piluchito $(<$ pilucho), guatita, también en jurar de guatita, y guatón 'ventrudo', guatero y guaterito en guatero y guaterito con uñas 'pareja con la que se convive', así como guatear 'desalentarse en un esfuerzo' $(<$ guata $)$, charchita, charchazo 'puñetazo' y descharchetear 'suspender' ( $<$ charcha $)$, cototudo $(<$ cototo $)$, pichangoso y pichangeo 'relativo a la pichanga' $(<$ pichanga), cahuinero 'chismoso' y cahuinear 'chismorrear' $(<$ cahuin $)$, copuchento 'chismoso' y copuchenta 'boca' ( $<$ copucha), catetear $(<$ catete), pololear 'seducir, convencer' ( $<$ pololo 'novio') y pilucho 'desnudo' (híbrido del español pelo + terminación mapuche). Asimismo se registró la metátesis regresiva tongua (<guatón) y el compuesto nominal guatepán 'guatón' (guata + pan). 
También en unidades fraseológicas se encontraron: guata en jurar de guata y asegurar de guata 'afirmar enfáticamente', como patá en la guata 'pésimo', pucho en pucho lacio 'impotente sexualmente', cachaña en hacer una cachaña 'eludir a un jugador contrario en deportes como el fútbol', pino 'guiso de carne y cebolla' en hacer el pino 'obtener gran ganancia', laucha 'ratoncillo' en al cateo de la laucha 'a la espera'. Además de la paronomasia calleuque (x callado) en pa calleuque 'en silencio'.

\section{2. 3. Náhuatl o azteca}

En cuanto al náhuatl o azteca se encontraron cinco voces: chapulín 'niño' ( $<$ 'saltamontes') y cuate 'mexicano' ( $<$ 'hermano'), por estereotipo de esta palabra, muy común entre hablantes mexicanos. Además, tiza 'arcilla blanca' en la expresión metafórica mano con tiza 'profesor', debido a que se trata de un utensilio asociado con el ejercicio de la docencia. También se identificaron los derivados chocolito 'persona de raza negra' $(<$ chocolate) y malacatoso 'delincuente' $<$ malacate 'cabestrante para extraer minerales u otros materiales' < malakatl 'huso', con influjo de la paronomasia con malo).

\section{2. 4. Guarani}

Solo se registraron cuatro voces de origen guaraní: che 'argentino', por estereotipo de esta palabra característica del español rioplatense, donde se utiliza como muletilla, y jaguar 'chileno', 'empresario chileno', junto a sus derivados jaguarito 'niño chileno' y el parasintético ajaguarado 'exitoso en lo económico', debido a que en determinada época de auge económico ('90) a nuestro país se lo comparó con la bravura de dicho felino.

\section{2. 5. Aimara}

Únicamente se identificaron tres lexías de origen aimara: los derivados cholito (<cholo 'peruano') y paquita (< paca 'mujer carabinero' $<$ alpaca, debido a que parte de la vestimenta de los antiguos policías se confeccionaba con la lana de dicho auquénido). Probablemente, la expresión festiva callulla 'nariz' provenga de cálla 'palo puntiagudo utilizado para escarbar y sembrar' del aimará callatha 'plantar'. 


\section{2. 6. Rapanui}

Tan solo se testimonió la presencia de una voz de este origen; se trata de moai 'pascuense', por estereotipo de estas monumentales estatuas de piedra con el pueblo rapanui o pascuense.

\section{2. 7. Origen incierto}

Posiblemente del quechua sea la voz cuico 'adinerado arribista' (en principio, a partir de la Guerra del Pacífico, designación despectiva para bolivianos y peruanos, pero que tal vez extendió su connotación peyorativa a los individuos de la clase alta), pilcha y pilchita 'prenda de vestir', chirimoyo 'cheque' (si bien también puede ser voz quiché; en este caso, se establece una analogía entre la inmadurez con que se recoge el fruto de la chirimoya con los cheques sin fondos y, luego, una extensión de este significado; cf. Oroz 1966), así como sohua 'futbolista sureño', y su diminutivo sohuita, forma invertida de huaso 'campesino' (aunque tal vez sea voz antillana). A su vez, de probable origen caribe o arahuaco sea papaya analogía fonética con papa 'fácil'. Otras voces de posible etimología indígena son los derivados Chilito y chilenita (<Chile, probablemente mapuche) en hacer chilenitas 'dar muestras de satisfacción' y tunazo 'balazo' (< tuna 'cactácea', quizás haitiano). Por último, tal vez de origen indígena sea pitearse 'estropear, echar a perder', quizás, pronominalización de pitear 'fumar', variación de pitar, tal vez, del guaraní pité 'chupar'. También en el sufijo -eco de patuleco se ha querido ver la influencia de un sufijo náhuatl para designar 'defecto', lo que no ha estado exento de discusión (cf. Wagner 1950).

\section{INVENTARIO LEXICOGRÁFICO DE LOS NEOLOGISMOS ESTILÍSTICOS DE ORIGEN INDÍGENA RECOPILADOS EN EL CORPUS}

\section{1. NATURALEZA y ESTRUCTURA DEL INVENTARio}

\section{1. 1. Naturaleza y objetivos}

En virtud de la índole dialectológica y estilística de nuestra recogida léxica, así como de su valor testimonial, nos hemos propuesto presentar los neologismos registrados en el corpus en toda la gama de sus posibilidades 
formales, funcionales y semánticas documentadas, sin actitud normativa ni selectiva.

\section{1. 2. Estructura lexicográfica del Inventario}

En términos generales, el Inventario sigue la técnica lexicográfica desarrollada por Prieto en diferentes trabajos relativos al préstamo léxico en la prensa de Santiago de Chile (1979, 1982-1983, 1992, 1993-1994, 2002-2003, 2004-2005, 2006 y 2007), con ligeras modificaciones. El Inventario contiene 132 artículos léxicos. Es preciso señalar que algunos de ellos corresponden a derivados o variantes formales. La finalidad de su inclusión estriba en la naturaleza misma de nuestra indagación, vale decir, en su carácter estilístico y lexicogenésico, además de la adopción de la capacidad para formar familias léxicas como criterio para medir la vitalidad de los neologismos.

\section{1. 2. 1. Estructura de los artículos}

Los artículos de nuestro inventario se estructuran de la manera que se detalla a continuación.

\section{1. 2. 1. 1. Ordenamiento de los lemas}

En concordancia con la práctica lexicográfica tradicional y a fin de facilitar su consulta, se han ordenado los lemas o cabezas de artículos en estricto orden alfabético.

\section{1.2. 1. 2. Lema}

La voz, frase o locución que sirve de lema del artículo va en mayúscula. Las variantes morfológicas y ortográficas de la unidad léxica se incluyen al final del artículo. Los vocablos homónimos, es decir, los que coinciden en el significante pero son de un distinto origen o significado, o bien manifiestan un comportamiento morfosintáctico diferente, se tratan en artículos separados (Véase cototo). Las unidades léxicas pluriverbales, como las locuciones, las frases hechas y los modismos, se ubican en el artículo correspondiente a una de las palabras que las constituyen, siguiendo este orden de preferencia: sustantivo, verbo, adjetivo, pronombre, adverbio.

\section{1. 2. 1. 3. Caracterización gramatical}

En general, la caracterización gramatical de las unidades léxicas se ha hecho según el sistema empleado tradicionalmente en la lexicografía hispánica. En el caso de las unidades léxicas pluriverbales se ha utilizado la nomenclatura propuesta por Casares (1950). 


\section{1. 2. 1. 4. Ordenamiento de las acepciones}

Cuando una unidad léxica registra diversas acepciones, todas ellas se reúnen dentro de un mismo artículo separadas por barra vertical doble, siguiendo una numeración correlativa con números arábigos.

\section{1. 2. 1. 5. Ubicación de las unidades pluriverbales}

Las unidades pluriverbales que se relacionan semántica y etimológicamente con el lema, se incluyen, separadas por barra vertical doble, a continuación de las acepciones, sin numeración.

\section{1. 2. 1. 6. Origen derivado y etimología}

Inmediatamente después del lema y antes de la caracterización gramatical, se incluye entre paréntesis la indicación del carácter derivado de la forma léxica, así como su étimo de origen, remitiendo a la fuente que consigna dicha etimología.

\section{1. 2. 1. 7. Otras marcas o determinaciones}

A fin de dar cuenta de la condición y valoración del empleo de las diferentes unidades léxicas, se usan las marcas habituales en la práctica lexicográfica, como las relativas a la condición del sentido (v. gr. fig. 'figurado'); al nivel lingüístico (v. gr. fam. 'familiar'); al valor estilístico o actitud del hablante (v. gr. eufem. 'eufemístico'); a la modalidad o clase de texto (v. gr. Period. 'periodístico'); o al ámbito de uso (v. gr. Polít. 'política'). También se incluye la marca neo. 'neologismo idiosincrático' para indicar que se trata de una forma léxica ocasional o de utilización circunscrita al diario La Cuarta, y de este modo diferenciarla del resto de voces y locuciones que en su mayor parte son de amplia difusión en el habla coloquial y popular del español de Chile.

\section{1. 2. 1. 8. Definición}

La mayoría de las definiciones del presente inventario son del tipo denominado definición sinonímica. En una proporción menor, corresponden a definiciones de carácter descriptivo.

Por razones de economía de espacio y para no ser innecesariamente repetitivos, cuando una misma definición es aplicable a más de una unidad léxica, se la incluye en el artículo cuya voz muestra un vínculo más cercano con dicha definición o en la que aparece alfabéticamente primero. En los artículos correspondientes a otras voces o locuciones que comparten la misma definición se remite al lema del artículo respectivo, colocándolo en cursiva. 


\section{1. 2. 1. 9. Ejemplificación}

Tras cada una de las acepciones se incluye un ejemplo de uso (en algunos casos más de uno) tomado del corpus analizado. Cabe destacar, que no se escatimaron esfuerzos en la selección de los mejores ejemplos, de manera de proveer un contexto de uso lo más ilustrativo posible del significado de cada unidad léxica. Asimismo, como uno de los objetivos principales del Inventario es documentar las diferentes unidades léxicas en todas sus dimensiones (formales, funcionales, semánticas y estilísticas), así como para facilitar su consulta, cuando en una cita se usan dos o más lexías se las repite en sus respectivos artículos.

\section{1. 2. 1. 10. Sinónimos y observaciones}

En caso de que corresponda, se incluyen, a continuación de la abreviatura Sin., las voces que al interior del Inventario alternan en el uso con la unidad léxica que sirve de lema al artículo. Por otra parte, al final de cada artículo, cuando sea el caso, se consigna, después de Obs., cualquier tipo de observaciones al tratamiento o descripción que se ha hecho de la unidad léxica correspondiente, en especial, respecto del procedimiento de creación léxica implicado o del contraste con el léxico académico.

\section{1. 2. 1. 11. Contrastes con el léxico académico}

El cotejo de las unidades aquí inventariadas con el léxico académico muestra los tres tipos de contrastes siguientes:

a) unidades léxicas que no figuran en el Diccionario académico de 2001 (DRAE), en cuyo caso no se la distingue con una marca en especial y se las considera formas léxicas que se construyen mediante algún procedimiento de creación léxica de índole morfológica.

b) unidades léxicas que formalmente están registradas en el mencionado Diccionario, pero que aparecen con un significado diferente; en tal caso se antepone un asterisco al lema correspondiente y se las considera como voces motivadas por un proceso de cambio semántico.

c) unidades léxicas que coinciden formalmente de manera casual con alguna unidad incluida en el DRAE, pero cuya motivación y origen es diferente (Véase chucho); se consigna tal circunstancia anteponiendo un asterisco y señalando dicha coincidencia casual en las observaciones.

d) unidades léxicas que aparecen registradas en el DRAE, pero que son reconocidas como americanismos generales o chilenismos; en este caso se antepone el asterisco respectivo pero se las analiza de acuerdo con el procedimiento de creación léxica implicado, sea éste de orden formal o semántico. 
5. 2. INVENTARIO LEXICOGRÁFICO EJEMPLIFICADO DE LOS NEOLOGISMOS REGISTRADOS EN EL CORPUS

\section{ABREVIATURAS Y SÍMBOLOS EMPLEADOS}

abrv.

acron.

adj.

adv.

aprec.

aum.

c.

cc.

cf.

c. i. s.

com.

Dep.

despec.

dimin.

euf.

f.

fam.

fest.

fig.

inf.

interj.

intr.

jerg. delict.

juv.

loc.

loc. adj.

loc. adv.

loc. conj.

loc. f.

loc. intr.

loc. $\mathrm{m}$.

loc. part.

loc. prnl.

loc. tr. forma abreviada

acrónimo

adjetivo

adverbio

apreciativo

aumentativo

columna

columnas

consúltese

con igual significado

sustantivo del género común

Deporte

despectivo

diminutivo

eufemístico

sustantivo femenino

familiar

festivo

sentido figurado

infantil

interjección

verbo intransitivo

jerga delictual

juvenil

locución

locución adjetiva

locución adverbial

locución conjuntiva

locución sustantiva femenina

locución verbal intransitiva

locución sustantiva masculina

locución participial

locución pronominal

locución verbal transitiva 
m.

neo.

Obs.

p.

p. ext.

Period.

Polic.

Polít.

pl.

pond.

pp.

prnl.

prep.

s.

Sin.

S. V.

ú. m. c.

ú. s. c.

ú. t. c.

V.

var.

var. de

var. gráf.

()

[]

$[\ldots]$

*

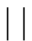

sustantivo masculino

neologismo ocasional

Observación

página

por extensión

Periodismo

Policial

Política

plural

ponderativo

páginas

pronominal

preposición

sustantivo

Sinónimo

sub voce

úsase más como

úsase siempre como

úsase también como

véase

variante

variante de

variante gráfica

antes de caracterización gramatical, encierra derivación o etimología; después de definición, localización de la cita.

en ejemplo de uso, proporciona el contexto necesario para mejorar la comprensión de la cita o da el significado de un chilenismo no incluido en el DRAE, ni en el presente Inventario.

indica omisión de palabras para abreviar una cita demasiado extensa.

indica unidad léxica que figura en el DRAE, $22^{\mathrm{a}}$ edición 2001; ya sea con una acepción diferente a la registrada en el corpus o caracterizada como americanismo (chilenismo u otro origen). separa acepciones o locuciones incluidas en el artículo. 


\section{SIGLAS Y REFERENCIAS EMPLEADAS}

Cammarota Lunfard. Federico Cammarota. Vocabulario familiar y del lunfardo. Buenos Aires: A. Peña Lillo Editor, 1970.

BDL. José Gobello y Luciano Payet. Breve diccionario lunfardo. Buenos Aires: A. Peña Lillo Editor, 1959.

DRAE. Real Academia Española. Diccionario de la lengua española. 22 ed. Madrid: Espasa Calpe, 2001.

Kany 1962. Charles Kany. Semántica hispanoamericana. Madrid: Aguilar, 1962.

Lenz DE. Rodolfo Lenz. Diccionario etimológico de las voces chilenas derivadas de lenguas indígenas americanas. Santiago: Imprenta Cervantes, 1905-1910, reedición dirigida por Mario Ferreccio.

Lira Estudio. Pedro Lira. Estudios sobre vocabulario. Santiago: Editorial Andrés Bello, 1973.

Morales DECH. Félix Morales. Diccionario ejemplificado de chilenismos y de otros usos diferenciales del español de Chile (4 tomos). Valparaíso: Universidad de Playa Ancha de Ciencias de la Educación, 1984.

Prieto Indigen. Luis Prieto. Indigenismos léxicos en las publicaciones periodísticas de Santiago de Chile. Boletín de Filología de la Universidad de Chile XXX: 105-240, 1979.

Prieto Quechui. Luis Prieto. Quechuismos en la prensa de Santiago de Chile. Boletín de Filología de la Universidad de Chile XLI: 97-196, 2006.

Rivera 1965. Hugo Rivera. Glosario de la novela "Chicago chico" de Armando Mendez Carrasco y otros autores. Boletín de Filología de la Universidad de Chile XVII: 281-361.

Román DCH. Manuel Antonio Román. Diccionario de chilenismos y otras locuciones viciosas (5 tomos). Santiago: Imprenta de San José, 19011918.

Vicuña Coa. Julio Vicuña. Coa, jerga de los delincuentes chilenos (Estudio y vocabulario). Santiago: Imprenta Universitaria, 1910. 


\begin{abstract}
A
*Achuntar (de chonta 'árbol del que se hacían flechas', y éste del quechua chunta 'árbol, variedad de la palma espinosa'; cf. DRAE s. v. achuntar) tr. fam. Acertar, dar en el blanco. Ú. t. c. intr. "Al escenario famosa novela de Carlos Cerda / Teatreros le achuntaron con la adaptación de 'Una casa vacía'” (La Cuarta, 23-XI-98, p. 29, cc. 1-3).

Ajaguarado, da (de jaguar, V.) adj. neo. Existoso en lo económico. “[...] afirmó ayer que ya pasó la tormenta económica internacional y destacó que Chile se ha mantenido con imagen ajaguarada, después de terminado el Foro Económico del Asia Pacífico (APEC)" (La Cuarta, 19-XI-98, p. 4, c. 4).
\end{abstract}

Año del ñauca, del (ñauca, del quechua ñaupa 'antiguo'; cf. Lenz DE p. 529, Prieto Indigen. p. 202 y Prieto Quechui. p. 163) loc. adj. fam. Dícese de lo que es muy viejo. "Hasta que se compró una citrola del año del ñauca, a la que bautizó como la 'Matadero' " (La Cuarta, 19-XI-98, p. 23, c. 4).

\title{
C
}

Cachaña, hacer una (cachaña, del quechua kacháña "hacerle quites al contendor"; cf. Prieto Indigen. p. 159 y Prieto Quechui. p. 128) loc. intr. fam. Evitar, eludir. "No debe adquirir ningún compromiso hoy. Si está entre la espada y la pared, haga una 'cachaña' y escape" (La Cuarta, 24-XI-98, p. 23, c. 2).

*Cahuín (del mapuche cahuiñ 'borrachera o junta para emborracharse'; cf. Lenz DE p. 158 y Prieto Indigen. p. 160) m. fam. despec. Copucha. "En relación a los rumores que corren sobre un posible regreso del 'Pipo' Gorosito, Edú dijo que no está ni ahí con los cahuines" (La Cuarta, 19-XI-98, p. 11, c. 5) || 2. Confusión, enredo. "Añadió que jamás Alejandra fue retenida por razones monetarias ni mucho menos, por lo que las motivaciones para la acción judicial son equivocadas al punto que, tras aclarar el cahuín, enviaron a la flamante mamá a su domicilio" ( $L a$ Cuarta, 5-XI-98, p. 7, cc. 2 y 3). 
Cahuinear (de cahuin, V.) tr. fam. Contar chismes, chismorrear. "[...] los dirigentes no tienen money para seguir pagando los 500 mil dólares que cuesta su salario al año. Mientras que, según se cahuineó, el propio temuquense estaría estudiando la posibilidad de no seguir en el club [...]" (La Cuarta, 19-V-04, p. 11, c. 3).

Cahuinero, ra (de cahuin, V.) adj. fam. despec. Copuchento. "Niños llegan a rugir de la risa con obra 'El libro de la selva' / Los cahuineros buitres sacan cualquier risotada en tanto que las jirafas se ganan de inmediato el aplauso con su aparición" (La Cuarta, 29-XI-98, p. 21, cc. 1 y 2).

Calleuque, pa (calleuque es topónimo de origen mapuche 'estar derritiéndose de nuevo'; cf. Lenz DE p. 795) loc. adv. vulg. fest. Con reserva, sin llamar la atención, en silencio. "A Cruz Coke le falta puro dar el sí por la iglesia ya que hace una semana se casó pa calleuque por el civil y casi naide se enteró" (La Cuarta, 22-VI-04, p. 18, cc. 4 y 5). Obs.: analogía fonética de callado con calleuque.

Callulla (probablemente de cálla 'palo puntiagudo utilizado para escarbar y sembrar' del aimará callatha 'plantar cualquier cosa'; de ahí derivaría también calluso 'flaco, huesudo' o calluzo 'dícese del animal que tiene el hocico alargado'; cf. Lenz DE pp. 164, 165 y 846 y Morales DECH T. I p. 769) f. vulg. fest. Nariz. "Pedirán que contraloría meta su callulla en Emeres / Diputados huelen manejo muy guácatela en Lepanto" ( $\mathrm{La}$ Cuarta, 24-XI-98, p. 5, cc. 3-5).

Cancha, rayar la (cancha del quechua homónimo 'patio cerrado'; cf. Lenz DE p. 171 y Prieto Indigen. p. 162 y Prieto Quechui. p. 130). loc. intr. fam. fest. Exigir el cumplimiento de algún compromiso o alguna norma. "[...] la belleza che le rayó la cancha al amor de su vida. Sin pelos en la lengua, le dijo al 'Negro' que uno de sus sueños era casarse, pero de blanco y por la iglesia” (La Cuarta, 18-V-04, p. 17, c. 1).

*Caracha (del quechua karacha 'sarna, tiña, roña'; cf. Lenz DE pp. 178 y 179) f. fam. despec. Cantidad muy escasa, cifra insignificante "[...] ya que a aquellos jugadores que tienen un sueldo alto les adeudan el 41 por ciento de agosto y los que ganan una caracha están al día" (La Cuarta, 19-XI-98, p. 14, c. 2).

Carpa, levantar (carpa, de etimología incierta, tal vez del quechua; cf. Lenz DE p. 182, Prieto Indigen. pp. 163 y 164 y Prieto Quechui. p. 131) loc. intr. fig. vulg. Experimentar el hombre la erección de su miembro viril. 
"Ojo, teclitos, con las pastillas para levantar carpa que ofrecerán en la calle / Sonó el control de la natalidad: Asaltan cotota farmacia y roban todo el Viagra" (La Cuarta, 23-XI-98, p. 3, cc. 1-5).

Cateo de la laucha, al (laucha, del mapuche laucha o llaucha 'ratoncillo'; cf. Lenz DE p. 426) loc. adv. vulg. A la espera, a la expectativa. Ú. m. con estar y andar. "Los pepes, que sueñan con volver cuanto antes al fútbol de honor, no han parado de entrenar desde que quedaron al cateo de la laucha, en la 'liguillla del terror' " (La Cuarta, 10-XII-98, p. 12, c. 3). Sin.: ojo al charqui.

*Catete (de catete 'harina tostada con caldo de chancho', también denominación popular para el demonio, probablemente del mapuche; cf. Lenz DE p. 183 y Román DCH. T. I p. 299) adj. fam. fest. Molesto, impertinente, insistente. "Siendo puntudos, catetes para que el primer disco -'Los tres' (1991)- tuviera su oportunidad [...]" (La Cuarta, 9-XII-98, p. 18, c. 2). Obs.: cf. Rivera 1965, p. 302.

Catetear (de catete, V.) intr. fam. fest. Molestar, insistir. "Garzón catetea a Brasil. Por su lado, Garzón también quiere que Brasil aporte pruebas que puedan ser utilizadas [...]" (La Cuarta, 7-XI-98, p. 2, c. 3).

Catetemente (de catete, V.) adv. fam. fest. Con insistencia, reiteradamente. "El estudio se basó en una encuesta al azar aplicada a 906 egresados de colegios técnicos en 1991 -a quienes se les siguió catetemente por cinco años-, a sus papis y a los establecimientos" (La Cuarta, 21-XI-98, p. 6 , cc. 4 y 5$)$.

Caturro (de caturra 'cotorra o loro pequeño'; cf. DRAE s. v.) adj. y s. Period. Dep. Relativo al Club Deportivo Santiago Wanderers. “[...] declaró el técnico de Wanderers, al finalizar ayer la práctica de los 'caturros'" (La Cuarta, 7-XI-98, p. 10, c. 4).

*Chacra (del quechua antiguo chakra 'huerta, sembradío'; cf. Lenz DE p. 235, Prieto Indigen. p. 172 y Prieto Quechui. p. 133) f. fig. fam. despec. Desorden, dícese de lo que se realiza sin organización ni seriedad. "Concerta pidió chutearla para el '99 / Rábanos puntean chacra de elecciones en la CUT / [...] El proceso corrió en un clima de incertidumbre, por el cuco de invalidez de las elecciones, ya que algunos dirigentes, que se echaron el pollo, no tenían concretadas sus renuncias en el Colegio Electoral de la CUT ni en la Dirección del Trabajo" (La Cuarta, 5-XII98 , p. 5 , cc. 5 y 6$)$. 
Chacriento (de chacra, V.) adj. despec. fam. Relativo a lo que se realiza en desorden y con absoluta falta de seriedad. "Colectivos chacrientos / Amigos de La Cuarta necesito reclamar contra todas, le repito, todas con mayúscula, líneas de colectivos de Padre Hurtado [...] Los choferes siempre andan enojados, malagestados, sucios y cobran a su pinta [...]" (La Cuarta, 16-VI-04, p. 6, c. 1).

Chapulín (del azteca chapulin 'saltamontes'; cf. Kany 1962 p. 79) m. neo. Niño de corta edad. "[...] como una forma de celebrar los 10 años que los chapulines del Programa Infantil Nacional de Drogas Anticancerosas (Pinda) llevan sacándose la mugre por sanar a estos angelitos" (La Cuarta, 7-XI-98, p. 5, c. 5). Sin.: chapulín, poroto. Obs.: tal vez por influencia de la serie televisiva mexicana "El Chapulín Colorado".

Charcha (del mapuche chalcha 'papada'; cf. Lenz DE p. 242 y Prieto Indigen. p. 176) Malo, deficiente, de mala calidad. "Benítez y Gualberto Jara sufrieron como orates con el juego de los 'piratas' y con la charcha presentación de los albos en el 'Sánchez Rumoroso' " (La Cuarta, 23XI-98, p. 15, c. 4 y 5). Var.: charchita.

Charchazo (de charcha, V.) m. aum. fam. Combo. "Él internó a Nilo y ahora se preocupará de calmar a los borrachines. Aunque sea a charchazos" (La Cuarta, 19-XI-98, p. 7, c. 4).

Charchita (de charcha, V.) adj. dimin. aprec. fam. despec. Charcha. "[...] La celebración de sus regalones quedó trunca, luego que los pirulos se presentaran con un equipo asaz charchita" (La Cuarta, 10-XII-98, p. 13 , c. 4).

Charqui, ojo al (charqui 'carne seca salada' del quechua ch 'arqui c. i. s.; cf. Lenz DE pp. 261-263 y Prieto Indigen. p. 176) loc. adv. fam. fest. Alerta, atento. Ú. m. con estar y andar. "[...] Pareto dijo que ya se puso de acordeón con los verdes de la $21^{\mathrm{a}}$ Comisaria, quienes andarán ojo al charqui y con unas ganas locas de llevarse detenidos a los pelafustanes que vendan petardos mulas [...]" (La Cuarta, 5-XII-98, p. 6, cc. 3 y 4). Sin.: al cateo de la laucha.

*Chascón (de chasca 'cabello greñudo' del quechua ch 'aska c. i. s.; cf. Lenz DE pp. 263 y 264 y Prieto Quechui. p. 136) adj. aum. fam. Dícese de la persona de pelo largo y greñudo. "Ayer se integraron Gloria Benavides y los chascones del grupo Illapu" (La Cuarta, 19-XI-98, p.18, c. 3). Obs.: cf. Rivera 1965, pp. 311 y 312. 
Chasquilla, maestro (chasquilla de chasca, V. chascón) m. fam. despec. Albañil o maestro que se caracteriza por su falta de preparación e ineficiencia. "Entre el 15 y el 20 por ciento de los incendios que se producen en Chago en época invernal tienen su origen en una mala manipulación de las estufas a gas por parte de los usuarios y en los arreglines cuchufletas que realizan maestros chasquillas, según cifras del Cuerpo de Bomberos de Santiago" (La Cuarta 22-VI-04, p. 6, c. 2). Obs.: s. v. chasquilla en DRAE 'flequillo'.

*Che (quizás del guaraní che 'yo', 'mi', en Argentina esta voz se utiliza para llamar o dirigirse a una persona; cf. Prieto Indigen. pp. 177 y 178, BDL. p. 30 y Cammarota Lunfard. p. 72) adj. neo. Argentino, relativo a la Argentina. "Solicitud de jueza che que investiga asesinato del general Prats / Suprema acogió exhorto para enviar a Argentina las huellas de Pinochet" (La Cuarta, 19-XI-98, p. 5, c. 1-4).

Chilenitas, hacer (chilenita, de chilena, en el fútbol 'tipo de disparo en que el jugador adopta una posición casi horizontal, y golpea luego el balón hacia atrás con una de sus piernas por encima de la cabeza'; cf. Prieto Indigen. p. 179, de Chile V. Chilito) loc. intr. fam. Manifestar satisfacción o contento por algún beneficio. "Los 'tanos' tendrán que enfrentar a la 'U' en el Nacional. Desde el punto de vista deportivo, salieron para atrás, pero sus dirigentes hacen chilenitas pensando en la recaudación" (La Cuarta, 10-XII-98, p. 11, cc. 2-5).

Chilensis (de Chile) adj. vulg. y juv. fest. Chileno, relativo a Chile. "'Tiene dos corazones, uno también en la cabeza', dice el 'Corriere dello Sport' refiriéndose a Iván Zamorano y reflejando el reconocimiento que hizo ayer la prensa italiana al esfuerzo y entrega física del goleador chilensis [...]" (La Cuarta, 6-XI-98, p. 23, c. 1). Obs.: forma tomada de la descripción zoológica y botánica de las ciencias naturales.

Chilito (de Chile, origen incierto, tal vez del mapuche chile 'unas gaviotas' o trile 'pájaro, xanthornus cayensis'; cf. Lenz DE pp. 279-284 y Prieto Indigen. p. 179) m. dimin. aprec. vulg. fest. Chile. "Boletos para la casa sacó el embajador de Chilito en España, Sergio Pizarro Mackay, quien fue retirado temporalmente por el gobierno [...]" (La Cuarta, 7-XI-98, p. 2, c.4). Sin.: Jaguarlandia.

* Chingar (según Lenz chingar o chingarse proviene del quechua chincay 'perderse, desaparecer'; cf. Lenz DE p. 300) intr. fest. fam. Fracasar, frustrarse algo. "Ahora, a cruzar los dedos para que no aparezcan problemas 
que chinguen la visita del gran 'Terminator"' (La Cuarta, 19-V-04, p. 15, c. 3). Obs.: DRAE, s. v. chingar, no consigna etimología indígena, solo la considera voz onomatopéyica.

*Chirimoyo (de chirimoya 'fruta del Anona chirimolia', origen incierto, tal vez del quechua o quiché; cf. Lenz DE p. 305 y Prieto Indigen. p. 181) $\mathrm{m}$. vulg. fest. Cheque. "El flamante vencedor se embolsó 1.300 dólares y agarró 12 puntos para el ranking de la ATP, mientras que Gamonal se hizo de un chirimoyo de 750 dólares más nueve puntetes para el ranking" (La Cuarta, 23-XI-98, p. 23, c. 1). Obs.: cf. Rivera 1965, pp. 312 y 313 y Oroz 1966, p. 417.

Choclero (de choclo, y éste del quechua chókklo 'maíz'; cf. Lenz DE p. 306 y Prieto Indigen. p. 181) m. fig. fam. fest. Diente. "El Colo tendrá que jugar con los chocleros apretados esta noche, en el 'Francisco Sánchez Rumoroso', si no quiere llevarse un tremendo mal rato con los 'piratas', que están afilando las garras para dar la mansa sorpresa" (La Cuarta, 21-XI-98, p. 15, c. 1).

Chocolito, ta (de chocolate, voz de etimología discutida, tal vez del azteca pócho-kakawa-atl 'bebida hecha de caco y ceiba'; cf. Lenz DE pp. 309 y 310 y Prieto Indigen. p. 182) m. y f. dimin. neo. fest. Persona de raza negra. "[...] pero nada que envidiarles a las top models, onda Claudia Schiffer, Cindy Crawford y la chocolita Naomí Campbell, pues son igual de regias y todavía tiran sus buenos petardos, tanto que incluso desfilan en traje de baño" (La Cuarta, 9-XII-98, p. 6, c. 4).

Cholito, ta (de cholo c. i. s. y éste, tal vez, del aimará chhulu 'mestizo'; cf. Lenz DE p. 311 y Prieto Indigen. pp. 183 y 184) adj. dimin. aprec. fam. Peruano. "[...] pasando el 'Pollo' Arancibia al ataque en reemplazo del cholito Maestri, que está con gota" (La Cuarta, 21-XI-98, p. 10, c. 4).

Choreado, da (de chorear, V. chorearse) adj. fam. Molesto, enfadado. “'Se han confirmado nuestras peores expectativas, en el sentido de que el Consejo de Ministros era solo un buzón de las peticiones del juez Baltazar Garzón', dijo notoriamente choreado Insulza" (La Cuarta, 7-XI-98, p. 2 c. 4 y 5) "Los jugadores del plantel local, que quedaron asaz molestos y choreados con la pobre presentación del pasado domingo [...]" ( $\mathrm{La}$ Cuarta, 9-XII-98, p. 12, c. 4).

Chorearse (de chorear 'refunfuñar, protestar', tal vez del quechua churacuy 'resistir, oponerse'; cf. Lenz DE p. 314) prnl. fam. Enojarse, enfadarse. 
"Exige explicación por PLR. Olarra se choreó con técnico de Independiente" (La Cuarta, 16-VI-04, p. 1, c. 4).

Choreza (de choro, V.) f. fig. fam. Acción notable, extraordinaria. "Además, aprovechando la ganga, los alcaldes firmaron un compromiso tendiente a potenciar chorezas como ésta, tendiente a tener chimpilos rosados y fuertes como Popeye" (La Cuarta, 5-XII-98, p. 7, c.3).

Choriflai (de choro, V. quizás haya influido en la formación de esta palabra la voz chuflay 'bebida alcohólica compuesta de cerveza, pisco o coñac con limonada', 'ebrio, achispado', tomada de una canción inglesa popular y humorística divulgada por marineros ingleses en los puertos chilenos, cuyo coro dice Shoo! Fly!; cf. Lenz DE pp. 323 y 324 y Román DCH T. II p. 56) adj. juv. fest. Choro 1. "Lo choriflai es que los retenes móviles se les unirán cinco camionetas que iluminarán con unos focos de este porte los sitios donde se mueve mandanga, macoña, 'paraguaya' prensada y gomas acelereitor [...]” (La Cuarta, 9-XII-98, p. 6, c. 3). Sin.: chorísimo. Var. graf.: choriflay.

Chorísimo (de choro, V.) adj. fam. pond. Choro 1. "Reviviremos temas que en su tiempo fueron hits. Es un desafío chorísimo, piensa que hace 35 años que no me presento en un teatro [...]" (La Cuarta, 7-XI-98, p. 20, cc. 1 y 2). Sin.: choriflai.

Choro, ra (del mapuche ch'uru 'caracol, concha'; cf. Lenz DE p. 314, Prieto Indigen. pp. 184 y 185 y Prieto Quechui. pp. 139 y 140) adj. fam. pond. Extraordinario, admirable, digno de destacarse. "Con estas cosas como que uno se olvida del escenario que, en el fondo, es el lugar donde comenzó y donde encuentra ese choro contacto con el público" (La Cuarta, 7-XI-98, p. 20, c. 2). Var.: choriflai, chorísimo. || 2. m. fig. Persona que se destaca por su audacia y valentía. Ú. t. c. adj. "Todo un barrio creció a su alrededor, compuesto especialmente por campesinos, probadores de suerte y choros que vivían en conventillos y chozas más humildes que sopita de pan" (La Cuarta, 24-XI-98, p. 24, c. 4).

*Chucho (del mapuche chuchu, V. chuncho, y de ahí al coa chucho 'cárcel'; cf. Lenz DE p. 318, donde recoge la acepción 'cárcel' o 'calabozo' y Vicuña Coa p. 80) m. vulg. y jerg. delict. Prisión, cárcel. "Una damisela que se encarama a las seis décadas y que se dedicaba al tráfico de drogas de primera calidad ha comenzado a ver el sol a cuadritos, porque fue puesta de patitas en el chucho" (La Cuarta, 23-XI-98, p. 3, c. 5). Obs.: cf. Rivera 1965, p. 314. 
*Chuchoca (del quechua chochoka 'maíz cocido y secado al sol'; cf. Lenz DE pp. 320 y 321 y Prieto Indigen. p. 185) f. fam. fest. Actividad, ajetreo. "La próxima cita, correspondiente al Future 2, se disputará [...] en las canchas del Club Unión de Viña del Mar [...] En la chuchoca raquetera internacional irán a la mocha la mayoría de los raqueteros que iniciaron el cuadro del Sport Francés"(La Cuarta, 23-XI.98, p. 23, c. 1).

Chuncho (del mapuche chuchu 'lechuza, Noctua pumea o Glaucidiun nanum y abuela'; cf. Lenz DE pp. 318-320 y Prieto Indigen. pp. 185 y 186) adj. y s. fam. Dep. Relativo al Club Deportivo de la Universidad de Chile. “"Chunchos' prefieren no hacerse ilusiones / La 'U' está preparando a 'Superman' para la liguilla” (La Cuarta, 5-XII-98, p. 10, cc. 2-4).

*Chupalla (del quechua achupalla 'la mata del maguei o pita (Agave americana)'; cf. Lenz DE, p. 328) interj. fam. euf. Frase exclamativa de asombro o sorpresa. "[...] Soy María Alarcón y estoy desesperada por mi hijo Rodrigo, que necesita urgente unas muletas [...] -Ah, chupalla. ¿Lo atropellaron?" (La Cuarta, 18-V-04, p. 6, c. 2). Obs.: DRAE, s. v. chupalla, no consigna etimología indígena y entrega otra acepción. Voz de motivación eufemística.

*Combo (de combo 'martillo pesado', del quechua kómpo 'bola', k'ompu 'tumor' o cumpa 'peñasco movedizo'; Lenz DE pp. 205 y 206 y Prieto Indigen. p. 167) m. fam. Puñetazo. "[...]le aforré un manso combo en el hocico que casi le di vuelta el caracho" (La Cuarta, 21-XI-98, p. 23, c. 4). Sin.: charchazo. Obs.: cf. Rivera 1965, p. 305.

Concho, a (concho, del mapuche concho 'sedimento de la chicha' y éste del quechua konchu 'borra, heces'; Lenz DE pp. 207 y 208) loc. adv. fam. Completa y absolutamente. "Sus huevos, denominados liendres, son pequeños cuerpos ovalados blanquecinos que se adhieren a concho al pelo" (La Cuarta, 29-XI-98, p. 5, c. 5).

Condorazo (de condoro, V.) m. aum. fest. fam. Condoro. "Como en Quilín el billete no sobra, al toque se encendieron las alarmas producto del manso condorazo acusado sin asco por Alberto Castillo veedor llanero que supervisó el pleito por la séptima patolia de las clasificatorias" ( $\mathrm{La}$ Cuarta, 16-VI-04, p. 11, c. 2).

Condorearse (de condoro, V.) prnl. vulg. Equivocarse, cometer un error. "Sin embargo, ahora no estoy tan segura que quiero casarme, porque me 
he dado cuenta que mi novio es bastante extraño $[\ldots]$ ¿Cree usted que me puedo condorear? (La Cuarta, 6-XI-98, p. 27, c. 4).

Condoro (de cóndor 'buitre andino, Sarcorramphus Gryphus', del quechua kúntur, c. i. s.; cf. Lenz DE pp. 208 y 209, Prieto Indigen. p. 167 y Prieto Quechui.p. 145) m. fam. Equivocación, error garrafal. "Fue así como, a los 66 minutos, Stankovic aprovechó un condoro de la defensa yugoslava para poner en ventaja a la Lazio" (La Cuarta, 6-XI-98, p. 23, c. 3).

*Copucha (del mapuche pucuchu 'vejiga' y ésta del aimará pucuchu 'ampolla'; cf. Lenz DE p. 211 y Prieto Indigen. pp. 167 y 168) f. fig. fam. fest. Chisme, habladuría, noticia falsa e inflada. "Copuchas, cahuines, dimes y diretes del mundo del espectáculo / A dos linduras les gustaría hacer el amor en misa y en baño de avión" (La Cuarta, 29-XI-98, p. 24, cc. 1-4). Sin.: cahuín.

*Copuchento, ta (de copucha, V.) adj. fig. fam. Chismoso, murmurador, entrometido. Ú. t. c. s. “[...] la profe [...] contó para despistar a los más copuchentos de los vecinos, que la cigüeña al fin se había acordado de ella [...]" (La Cuarta, 6-XI-98, p. 7, c. 2). Sin.: cahuinero.

*Copuchenta (de copucha, V.) f. fig. vulg. Boca. "Pero a la hora de los quiubos, cuando el saquero Salvador Imperatore estaba a la mitad de la cancha con el pito en la copuchenta, se dio cuenta de que faltaban los astros de Temuco. Por más que se hizo el cucho, no pudo más. Simplemente indicó en sus registros que Deportes Temuco no se presentó a jugar" (La Cuarta, 29-XI-98, p. 15, c. 5).

Coquero, ra (de coca, cocaína 'estupefaciente en forma de clorhidato, preparado con el alcaloide de la coca', del quechua kúka 'hoja seca de la Erythoroxylon coca' y ésta probablemente del aimará; cf. Lenz DE p. 191 y Prieto Indigen. p. 165) adj. jerg. delict. y vulg. Dícese del drogadicto que consume de cocaína. "Se iba a hacer el pino este verano / Encanó 'Mamá Nacha', la madrina de coqueros / [...] Una damisela que se encarama a las seis décadas y que se dedicaba al tráfico de drogas de primera calidad [...]" (La Cuarta, 32-XI-98, p. 3, c. 5).

Cototo (del mapuche t'ot'o 'hinchazón, protuberancia', tal vez por contaminación con el quechua coto 'bocio, papera'; cf. Lenz DE p. 214 y Prieto Indigen. p. 168) m. Hinchazón producida en alguna parte del cuerpo, en especial, la cabeza o el rostro, como consecuencia de un golpe. "Entonces mis padres me dijeron que el gordi era loco y que traía mala suerte, pues volví a hacerme un cototo, ahora en mi carita" (La Cuarta, 19-XI-98, p. 23, c. 4).

Cototo, ta (de cototo, V.) adj. fam. pond. Estupendo, excelente, muy bueno. "Chiloé, Ancud y la zona de los canales ya no esconden secretos para 
las cámaras y sistemas del cototo FaSat-Bravo, que está orbitando el planeta a poco más de 800 kilómetros de altura" (La Cuarta, 7-XI-98, p. 6, c. 5). Var.: cototudo. Sin.: macanudo. || 2. Grande, de gran tamaño. "[...] manifestó al referirse a medidas de este tipo adoptadas en comunas cototas, onda Santiago y La Florida" (La Cuarta, 19-XI-98, p. 9, c. 6).

Cototudo, da (de cototo, V.) adj. aum. fam. Cototo, ta. ."El lolo González [...] en un cototudo encuentro se sirvió ayer al español Rubén Fernández en dos sets [...]" (La Cuarta, 21-XI-98, p. 9, c.2). Sin.: macanudo.

*Cuate (del nahuátl cóatl 'serpiente', 'mellizo'; cf. DRAE s. v. cuate) adj. y s. fam. Mexicano, relativo a México. "Se comprometió con Don Francis hace 8 meses / Marco Antonio Solís faltará a la Teletón cuate por la Chilena / El mexicano Marco Antonio Solís faltará a la Teletón mexicana, pero no se perderá la nuestra" (La Cuarta, 24-XI-98, p. 20, cc. 1-3).

*Cuico, ca (de cuíco 'apodo despreciativo para los bolivianos usado en tiempos de la Guerra del Pacífico, es voz utilizada en otros lugares de América como denominación despectiva o con otros sentidos; de origen incierto tal vez indígena, aunque Lenz se manifiesta dudoso acerca de su origen; cf. Lenz DE p. 220, Kany 1962 p. 201 y Lira Estudio p. 84) adj. fam. despec. Dícese de la persona de clase alta que se destaca por su arribismo. “'Aló, mi viejo! ¿'La Cuarta', la cuica? -Evidentemente, posom. ¿Why? -Estoy llamando de la Municipalidad de Vitacura, posoye, para informar de un concurso de coros familiares que entregará interesantes cifras de dinero a los ganadores" (La Cuarta, 29-XI-98, p. 7, c. 5). Obs.: cf. Rivera 1965, p. 310.

Curagüilla (curagüilla o curahuilla 'sorgo o saina (sorgun vulgare), utilizado como alimento para aves o en la fabricación de escobas', del quechua curahua 'variedad de maíz muy duro', y éste del mapuche cura 'piedra' + hua 'maíz'; cf. Lenz DE p. 227 y Prieto Indigen. p. 169) m. fam. despec. Alcohólico, en particular, el reincidente que no da muestras de rehabilitarse. "Lo que más molesta es que los curagüillas creen que los jardines de la plaza y de nuestras viviendas son baños y basureros públicos y los dejan llenos de sus inmundicias" (La Cuarta, 10-XII-98, p. 7, c. 4). Obs.: analogía fonética de curado con curagüilla.

\section{D}

Descharchetar (de charcha, V.) tr. vulg. Suspender, terminar. "[...] los piteos del senador Carlos Bombal (UDI) para que el Gobierno descharchete los 
contratos de compra de armamento a empresas españolas y británicas, a raíz de la detención de Pinochet" (La Cuarta, 7-XI-98, p. 6, c. 4).

\section{G}

*Guacho (del quechua huajcha 'niño huérfano', luego huacho 'objeto solo que debería estar pareado'; cf. Lenz DE p. 360 y Prieto Quechui. p. 150) adj. fam. Desparejado, solo. "¿Qué consejo guacho le da a la barra pop para que no le vendan gato por liebre en las próximas fiestas navideñas?" (La Cuarta, 7-XI-98, p. 5, c. 1). Var. gráf.: huacho (La Cuarta, 5-XII98 , p. 15 , c. 6$)$.

*Guagua (del quechua wáwa c. i. s.; cf. Prieto Indigen. p. 189 y Prieto Quechui. p. 147) f. fam. Niño de pecho, lactante. "Guagua calcinada en incendio. Una lactante de tres meses, identificada como Luz María Contreras, murió calcinada anoche al incendiarse la casa que habitaba [...]" (La Cuarta, 21-XI-98, p. 7, c. 3). Obs.: cf. Rivera 1965, p. 324.

Guagüita (de guagua, V.) f. dimin. aprec. fam. Guagua. "Potente programa ha traído 100 guagüitas en una década / Fertilización asistida arregla el panizo a parejas infértiles" (La Cuarta, 29-XI-98, p. 7, cc. 1-3).

Guaracazo (de guaraca 'zurriago, látigo', del quechua warak'a; cf. DRAE s. v. guaracazo y Prieto Quechui. p. 149) m. aum. fam. Golpe "[...] mansos ni que guaracazos de corriente cuando retorna el servicio, que son súper peligrosos para las personas y perjudiciales para la vida útil de los electrodomésticos" (La Cuarta, 23-XI-98, p. 2, c. 3) || 2. Explosión “Apenas alcanzó a mostrarles el artefacto a sus acompañantes cuando éste pegó el manso guaracazo, destrozándole sus manos y dejándolo con serias quemaduras en sus piernas y la cara" (La Cuarta, 21-XI-98, p. 2, c. 1).

*Guata (del mapuche huata c. i. s.; cf. Lenz DE p. 386 y Prieto Indigen. p. 190) f. fam. Panza, vientre. "La idea es que la gallada se agarre la guata a dos manos y que se regrese a su palacete con una mansa sonrisa" (La Cuarta, 10-XII-98, p. 18, c. 3). || 2. f. vulg. y juv. Millón de pesos. "Nadie le achuntó a Loto y uno con 76 guatas en la revancha / [...] En la categoría 'Revancha' hubo un suertudo que se llevó el pozo acumulado de 76 millones 327 mil 989 pesos [...]" (La Cuarta, 6-XI-98, p. 5, c. 1). Sin.: guatón. || jurar de guata loc. tr. vulg. y juv. Afirmar de modo 
enfático. "El Precandidato presidencial por la derecha, Joaquín Lavín, y el ex senador DC Arturo Frei Bolívar, primo de Don Lalo, juraron de guata que el encuentro que tuvieron ayer, con motivo de valorar el gesto que hizo el ex parlamentario al visitar al general Augusto Pinochet en el hospital de Londres, fue solo eso y nada que ver con que era parte de campañas políticas solapadas" (La Cuarta, 23-XI-98, p. 4, cc. 4 y 5). Var.: asegurar de guata. Obs.: cf. Rivera 1965, p. 324. || como patá en la guata loc adj. y adv. fam. fest. Pésimo. "Por otro litro, la cosita linda comentó que "no es necesario ser una profesional para estar en el escenario ni en la televisión' lo que debe haber caído como patá en la guata a los tontos que se pasan quebrando por sus titulachos" (La Cuarta, 16-VI-04, p. 18, c. 1).

Guatear (de guata, V.) intr. fam. despec. Declinar el empeño o impulso inicial puesto en alguna meta. "Escolares Nicolás Cobo y Felipe Reyes brillaron en feria científica mundial / Se las mandaron con pesticida de canela / [...] Los muchachos, que si no guatean con las ganas podrían darle a Chile en el futuro el Premio Nobel de Bioquímica - de esa onda-fueron recibidos ayer en La Moneda por Luisa Durán de Lagos [...]" (La Cuarta, 18-V-04, p. 2, cc. 2-3).

Guatepán (de guata y pan) m. fest. despec. fam. Guatón 1. "Nutricionistas aconsejan contra obesidad y males al cucharón / Ojo, guatepanes: A comer pescado" (La Cuarta, 19-V-04, p. 2, cc. 3-4).

Guatero con uñas (guatero de guata, V.) loc. m. y f. vulg. fest. fig. Expresión festiva para referirse a la persona con la que se convive maritalmente y con la que se duerme en la misma cama. "Denuncian venta de bolsas mulas que no aguantan el agua caliente / Confirmado: Guateros con uñas son los más seguros contra el frío / Confirmado: El popular y siempre bien ponderado guaterito con uñas sigue siendo lejos el elemento más seguro a la hora de combatir el frío [...]" (La Cuarta 22-VI-04, p. 6, c. 1). Var.: guaterito con uñas. Obs.: DRAE recoge guatero con la acepción "Bolsa de caucho que, llena de agua fría o caliente y con fines terapéuticos, se pone sobre la frente, el vientre o los pies".

Guatita (de guata) f. dimin. aprec. fam. Guata 1. "Con la ansiedad típica del que empieza a adentrarse en una aventura y la guatita apretada de los puros nervios [...]" (La Cuarta, 29-XI-98, p. 6, c. 3) || jurar de guatita loc. tr. vulg. y juv. Jurar de guata, V. guata. "Los integrantes del plantel de Deportes Iquique, juran de guatita que el Colo no se la va a llevar pelada y deberá bregar como insano para quedarse con los puntetes y 
el título de campeón" (La Cuarta, 9-XII-98, p. 12, c. 3). Var. expresiva de jurar de guata.

*Guatón, ona (de guata) adj. aum. fam. Barrigudo, ventrudo. "El Daniel -sus amigos de Iquique le dicen guatón- me pidió compromiso hace un año [...] parece que nadie le amarró las manos cuando era guagua, porque este gordo frescolín iba manejando como pulpo [...]" (La Cuarta, 19-XI-98, p. 23, c. 4). Obs.: cf. Rivera 1965, p. 325. Sin.: guatepán, V. Var.: tongua. || 2. m. vulg. y juv. Guata 2. "[...] por concepto de arriendo de los aparatos [...] y su mantención la industria del sector se embolsó 53 guatones de dólares el año pasado" (La Cuarta, 6-XI-98, p. 5, c. 2).

\section{$\mathbf{H}$}

Huinchas por algo, estar alguien que corta las (huincha, del quechua wincha 'cinta para sujetar el cabello'; cf. Lenz DE p. 404, Prieto Indigen. pp. 192 y 193 y Prieto Quechui. p. 153 y 154) loc. intr. fig. fam. fest. Estar alguien muy ansioso o deseoso por obtener algo. "Andrea Vásquez estaba que cortaba las huinchas para abrochar su cinturón y despegar" (La Cuarta, 29-XI-98, p. 6, c. 4).

\section{$\mathbf{J}$}

*Jaguar (del guaraní yaguar 'león americano, Felis onca'; cf. Prieto Indigen. pp. 193 y 194) m. fig. neo. fest. Empresario chileno. "Lo mismo, pero por estratos socioeconómicos, se traduce en el sector alto en un 68 por ciento de confianza en los jaguares, 58 en Banco Central, 56 en inversión extranjera, 46 en Hacienda [...]" (La Cuarta, 24-XI-98, p. 8, cc. 2 y 3) || 2. adj. Chileno. Ú. t. c. s. "[...] onda que entre enero y noviembre de este calendario transportó más de dos millones 100 mil jaguares, cifra superior al total de pasajeros de todo 1997[...]" (La Cuarta, 5-XII-98, p. 6, c. 5 y 6$)$.

Jaguarito, ita (de jaguar, V.) m. dimin. neo. Niño chileno. "Los cabros de Agua Viva quieren que en todos los hospitales de Chilito la cosa sea igual, con el mismo ambiente y buena onda, por eso invitaron a los con así el 
cuore a participar llamando al 732-2821 para sacar caleta de sonrisas a los jaguaritos" (La Cuarta, 7-XI-98, p. 24, c. 2).

Jaguarlandia (de jaguar, V. y landia 'sitio de') f. neo. fest. Chilito. "Berta Belmar señaló que la secretaría de Estado dará dura batalla para que los estándares de calidad sean respetados [...] Por eso, los 200 inspectores que el Minvu tiene en Jaguarlandia andan con las tremendas pepas [...]" (La Cuarta, 19-XI-98, p. 5, c. 5).

*Luma (del mapuche homónimo 'una madera muy dura'; cf. Lenz DE p. 442). f. fam. Castigo. "[...] recién ahora se le tomó el peso al haber entonado el himno patrio el pasado domingo 6 de junio, dado que se chupeteó a la FIFA que Chile no tenía la pasá para canturrearlo y, por ello, ahora se arriesga a una luma de 15 mil dólares (unos \$9.600.000)" (La Cuarta, 16-VI-04, p. 11, c. 2). Obs.: DRAE recoge la acepción 'Árbol chileno, de la familia de las mirtáceas, que crece hasta 20 metros de altura. Su madera es dura, pesada y resistente'.

\section{M}

Macanudo, da (de macana 'arma contundente, garrote grueso' del taíno o el quechua makana, y de ahí al lunfardo; cf. Lenz DE pp. 455-458 y Prieto Indigen. p. 197, BDL. p. 51, Cammarota Lunfard. p. 130 y Lira Estudio pp. 192 y 193) adj. aum. fam. pond. Cototo, ta 1. “[...] usted es una cabra sana y macanuda y que no está pensando en el billete de su pololo, sino en sus encantos masculinos" (La Cuarta, 24-XI-98, p. 23, c. 4). Obs.: cf. Rivera 1965, p. 331.

Malacatoso, sa (de malacate "cabrestante movido por caballos para extraer minerales, agua de pozos, arena, etc.", del nahuatl malakatl 'huso', compuesto de malina 'torcer hilo' y ákatl 'caña'; cf. Lenz DE p. 466 y Prieto Indigen. p. 199) adj. y s. fam. Delincuente. "Funcionarios de investigaciones capturaron a siete antisociales [...] Los malacatosos fueron identificados como [...]" (La Cuarta, 24-XI-98, p. 3, cc. 1 y 2). 
Mano con tiza (tiza del náhuatl tiçatl 'greda blanca'; cf. Lenz DE p. 721 y Prieto Indigen. p. 220) loc. m. fig. vulg. Profesor. "Arriagada calificó la situación de los manos con tiza como 'muy dramática porque es una de las profesiones peor pagadas de Chile', dijo. 'No voy a humillar a los maestros para que paguen, bajándoles aún más los sueldos' " (La Cuarta, 19-XI-98, p. 9, c. 5).

*Mate (del quechua máti 'calabacita', de ahí también pasó al lunfardo; cf. Lenz DE pp. 483 y 484, Prieto Indigen. p. 200, Prieto Quechui. p. 159 y Cammarota Lunfard. p. 136) m. fig. fam. Cabeza. "No se me pasa por el mate perder' / Mario Mosquera ha emprendido muchos desafíos en su larga vida y este, el de soñar con la presidencia de la ANFP, sin lugar a dudas es uno de los más complicados [...] Pero eso no lo amilana. Por el contrario, lo motiva mucho más a dar una dura pelea, que jura ganará lejos" (La Cuarta, 23-XI-98, p. 11, cc. 1-5). Obs.: cf. Rivera 1965, p. 333.

Matearse (de mate, V.) prnl. fam. y juv. Pensar, reflexionar, concentrarse en una materia o en la solución de un problema. "Para esta pregunta hay cuatro respuestas, pero una sola es la correcta ¡Matéate tratando de encontrarla! ¿Cómo se llama un grupo de cerdos?” (La Cuarta, 7-XI-98, p. 11, c. 1).

Mateíto, ta (de mateo, V.) adj. fig. dimin. aprec. fam. Mateo. "Concertacionistas obtuvieron 52,47\% / Chascas de FEUC seguirán ondita 'democratizadora' [...] La Lista, la K3, representando a independientes y concertacionistas, obtuvo el 52,47 de los sufragios, imponiéndose a la UC1, que alcanzó 46,78 por ciento de las preferencias, dentro de un universo de 15.800 mateítos, con 9.103 votos válidamente escrutados" (La Cuarta, 21-XI-98, p. 5, cc. 1 y 2).

Mateo, tea (de mate) adj. fig. fam. Dícese del estudiante o la persona estudiosa y aplicada. "Un masivo encuentro con mateos de la Universidad de La Frontera fue la primera actividad que realizó ayer la comitiva de artistas solidarios que motivan a la sureña gallada a cooperar con la Teletón" (La Cuarta, 19-XI-98, p. 18, c. 1). Var.: mateito.

*Moai (voz de origen rapanui; cf. DRAE s. v. moái 'Figura tallada de medio cuerpo que representa ancestros de la cultura pascuense') $\mathrm{m}$. neo. Pascuense, de origen rapanui. "Pícaro moai reconoce que desde que hizo desnudo le cambió la vida / Hotuiti: 'Ahora todas las mujeres me miran 
el poto"' (La Cuarta, 22-VI-04, p. 15, cc. 1-3). Obs.: DRAE no indica etimología y registra variante con tilde gráfico.

Mote, cachar el (mote del quechua mot'e, mut'i 'maíz hervido' y de ahí al mapuche; Lenz DE pp. 512 y 513 y Prieto Indigen. pp. 201 y 202.) loc. intr. juv. Averiguar un asunto, dilucidar algo. "Mientras, el lunes se cortará en Santiago la cinta inaugural de la investigación que la Cámara de Diputados iniciará para cachar el mote que dio pie al tete del racionamiento eléctrico" (La Cuarta, 29-XI-98, p. 5, c. 2).

Nana (del quechua nanay 'dolor'; cf. Lenz DE p. 520 y Prieto Quechui. p. 162). f. fam. inf. Herida, dolencia física. "[...] se les terminó de atravesar el galeno de River a quien se le apuntó con el dedo de frentón por la seguidilla de nanas que no han dejado vivir en paz al 'shileno' desde que regresó de Europa” (La Cuarta, 19-V-04, p. 11, c. 2).

*Ñeque (de origen incierto, tal vez antillano o mapuche; cf. Lenz DE pp. 530-531) m. fam. fest. Fuerza, energía. "La Defensa Civil de la Quinta Región, a pesar de que no tiene ni siquiera un tocomocho para auxiliar a los accidentados, a puro ñeque colaboró con los muchachos que llegaron pidiendo agüita y una silla para descansar tras la larga caminata al Santuario" (La Cuarta, 9-XII-98, p. 24, c. 3).

\section{$\mathbf{O}$}

Ojota, mostrar la (ojota 'sandalia de cuero', probablemente del quechua uxota 'calzado'; cf. Lenz DE pp. 537 y 538 y Prieto Quechui. p. 163) loc. intr. fig. fam. despec. Dar muestras de ordinariez, falta de urbanidad y cortesía. "Sin embargo, usted también mostró la ojota y evidenció ser 
cuma total cuando le cascó a la infiel. No era necesario, bastaba con decirle chaíto, no más" (La Cuarta, 21-XI-98, p. 23, c. 4).

\section{$\mathbf{P}$}

*Pampear (de pampa 'llanura', 'campo abierto', del quechua pámpa c. i. s.; cf. Lenz DE pp. 553 y 554 y Prieto Indigen. p. 203) intr. fig. vulg. Extenderse, ampliar algo su predominio o importancia en cierto lugar y lapso de tiempo. "Como broche de oro para este año en que pampeó la música tropical, usted puede llevarse a palacio el primer disco compacto de la Nueva Colección Bomba que el próximo jueves le trae su diario pop" (La Cuarta, 23-XI-98, p. 28, cc. 1 y 2).

*Papa (del quechua pápa 'patata, tubérculo de la planta solanácea Solanum tuberorum'; cf. Lenz DE pp. 557-562, Prieto Indigen. p. 204 y Prieto Quechui.pp. 165 y 166) f. fam. Verdad, información verdadera. "Se supo la papa / Saccone se fue con cadenita como recuerdo / El autor del choreo de la gargantilla a Jorge Vargas, que el año pasado estuvo a préstamo en Coquimbo, fue el trasandino Mario Saccone [...]" (La Cuarta, 21-XI98, p. 15, c. 2). Var.: papita. || 2. Novedad "En dos semanas más vamos a terminar un estudio de grabación con la última papa en tecnología" (La Cuarta, 7-XI-98, p. 20, c.3) "Air Supply [...] su más reciente papa discográfica es 'The book of love'" (La Cuarta, 23-XI-98, p. 26, c. 5). || papa misma loc. f. fam. Solución. "Interrogado si el programa es la papa misma, Mosquera señaló que es cototo: 'Se verá la modernización jurídica de los clubes a través de Sociedades Anónimas Deportivas [...]"' (La Cuarta, 23-XI-98, p. 11, c. 3) \|| agarrar papa loc. intr. fam. fest. Atreverse, envalentonarse. "Estoy confundido y todo el mundo me anda diciendo qué hacer. Todo porque agarré papa con una hembra. Lo malo es que tiene como guardaespaldas, porque ya me ha mandado a pegarle a dos gallos [...]" (La Cuarta, 23-XI-98, p. 31, c. 4). || soltar la papa loc. intr. fam. fest. Decir la verdad, confesar un secreto. "[...] en los próximos días será entrevistado por Scotland Yard. Los sabuesos tratarán de hacerlo soltar la papa sobre la muerte de Lady Di [...]" ( $L a$ Cuarta, 19-V-04, p. 8, c. 1). \| rayar la papa loc. intr. fam. fest . Insistir porfiadamente en algo sin mucho sentido. "Tanto en Calama como en Ciudad Gótica ya se sintonizó el mismo canal para rayar la papa con el único tema que a esta altura importa: ¿Quién tiene más power para quedarse con la estrella del Apertura 2004?" (La Cuarta 22-VI-04, p. 12, c. 2). Obs.: grafía registrada en el diario. 
*Papaya (de papaya 'fruto comestible del Carica papaya', probablemente del caribe o el arahuaco; cf. Lenz DE p. 563 y Prieto Indigen. p. 204 y 205) adj. fam. fest. Fácil. "Y es que el problema de la fertilidad en la pareja no es nada de papaya de asumir [...]" (La Cuarta, 29-XI-98, p. 7, c. 1). Obs.: analogía fonética del chilenismo papa 'fácil' con papaya.

Papita pal loro (papita de papa, V.) loc. adj. vulg. fest. Papaya. "[...] él se encargaría de empaquetar a su brother y de encausarlo por el buen camino para que dé el sí ante el Todopoderoso. Cosa que no será papita p'al loro" (La Cuarta, 18-V-04, p. 17, c. 1).

Paquita (de paca c. i. s., probablemente del aimara alpaca 'variedad doméstica de vicuña'; cf. Lenz DE pp. 128 y 129 y Prieto Indigen. pp. 157 y 158) f. dimin. aprec. vulg. y juv. Mujer carabinero. "-A propo, ¿siempre quiso ser paquita?" (La Cuarta, 6-XI-98, p. 5, c. 4).

*Patuleca (V. patuleco, ca) f. neo. vulg. despec. Pierna. "El tenis ha tenido un éxito constante y son varios los triunfos que se han obtenido en un tiempo prolongado, además que están defendiendo el título en cancha y comenzaron con la patuleca derechita" (La Cuarta 18-V-04, p. 13, c. 2). "[...] Por esta razón no los detuvieron, pero igual los hicieron poner patulecas en polvorosa" (La Cuarta, 19-V-04, p. 8, c. 1).

*Patuleco, ca (de pata, es probable una influencia indígena en el uso del sufijo - eco para denominar 'defectos', tal como lo sugiere Wagner 1950; sin embargo, no está claro dicho influjo) adj. fam. despec. Dícese de la persona o animal con algún defecto en los pies. "La cuenta, sin embargo, la abrió el Patizán a los 17 minutos, luego que Kastajic empalmara un cototudo centro rasante desde la derecha, dejando patuleco al arquero Marcheggiani" (La Cuarta, 6-XI-98, p. 23, cc. 1 y 2). Obs.: aparece en el DRAE, s. v. patuleco, con acepción similar, pero no se consigna posible etimología indígena.

Peñi (del mapuche peñi 'hermano'; cf. Lenz DE p. 664 s. v. quilla.) adj. neo. fest. Mapuche, relativo a este pueblo. Ú. t. c. s. "Los peñis de la Oficina de Asuntos Etnicos de la Municipalidad de La Pintana culminarán hoy un guillatún, a contar de las 18 horas, para pedir agua [...]" (La Cuarta, 29-XI-98, p. 5, c. 1). Obs.: término usado como tratamiento entre mapuches, pero asociado como estereotipo de dicho pueblo.

*Pichanga (probablemente del mapuche pichi, púchi, púthi 'poca cosa, chiquito' o pichin, pichigen 'ser poco, chiquito'; cf. Prieto Indigen. p. 
208-210, para la justificacción de esta etimología) f. fam. despec. Fiesta informal, improvisada. "Cortó por lo sano, ante amenazas de mayonesos de dejar la escoba / Gobierno decidió no prestar pelota para 'pichanga' del Parque Forestal [...] El subsecretario del Interior, Belisario Velasco, informó que el brillo no se puede realizar en el céntrico parque, pues representa una amenaza para la ciudadanía" (La Cuarta, 7-XI-98, p. 4, cc. 1-4). || 2. Encuentro informal de fútbol o básquetbol entre dos equipos que juegan por práctica o simple diversión sin ceñirse, en estricto rigor, a las reglas prescritas para estos deportes. "Salud: hoy no juegue pichangas ni haga deportes violentos. Puede producirse una lesión" (La Cuarta, 29-XI-98, p. 27, c. 1). Obs.: DRAE s. v. registra forma coincidente con otra etimología y acepción, del quechua 'escoba de barrer'.

Pichangeo (de pichanga, V.) neo. fest. despec. Actividad futbolística. "Seguidor del pichangeo patrio, el fogoso de la 'Xuxuca', cree que podría ganarse un espacio. 'En Chile se juega un fútbol fuerte, ideal para mi estilo"” (La Cuarta, 16-VI-04, p. 9, c. 1).

Pichangosa (de pichanga, V.) adj. fam. despec. Dícese del encuentro informal de fútbol o básquetbol. "[...] la práctica pelotera realizada ayer en la cancha 2 del Monumental [...] En la animada pichangosa, disputada en el recinto de Macul [...]" (La Cuarta, 19-XI-98, p. 13, c. 2).

*Pilcha (probablemente del quechua pillchay 'cardos de lana', y de ahí también al lunfardo pilcha 'ropa, atavío'; cf. Lenz DE pp. 592 y 593, BDL. p. 60 y Cammarota Lunfard. p. 164) f. fam. despec. Prenda de vestir, por lo general, en mal estado, deslucida. "Mario Sánchez se está amononando y arreglando sus pilchas para emprender el largo viaje a Tokio [...]" (La Cuarta, 24-XI-98, p. 13, c. 4). Var.: pilchita. Obs.: cf. Rivera 1965, p. 347.

Pilchita (de pilcha, V.) f. dimin. aprec. fam. Pilcha. "Las pilchitas que robaron los malditos eran con finos hilos de seda / Policía busca pistas con los ojos bien abiertos / Polis se ofrecen para salir a buscar pistas / Roban pirula tienda de ropita íntima femenina: 25 millones" (La Cuarta, 6-XI-98, p. 3, cc. 1-3).

Piluchito (de pilucho, V.) adj. fam. dimin. Pilucho. "Ambas se los disputaban. 'En el infierno andaremos piluchitos', decía Marlen ataviada con un ajustado traje de cuero rojo que le quedaba como tres tallas más chico" (La Cuarta, 22-VI-04, p. 19, c. 3). 
*Pilucho, cha (probablemente es formación híbrida de pelo y terminación mapuche de adjetivo, peluchi > piluchi> pilluchi; cf. Lenz DE p. 596 y Prieto Indigen. p. 211) adj. fam. Desnudo. "David Duchovny ve hasta marcianos piluchos / 'Agente Mulder' admite ser como tonto para pornografía” (La Cuarta, 29-XI-98, p. 21, cc. 4-6). Var.: piluchito.

Pino, hacer el (pino 'fritura de carne picada y otros ingredientes que sirve de relleno', del mapuche pinu "pajitas menudas"; cf. Lenz DE p. 601 y Prieto Indigen. p. 211) loc. intr. fig. fam. Obtener gran ganancia de un negocio. "Se iba a hacer el pino este verano / Encanó 'Mamá Nacha', la madrina de coqueros / [...] Una damisela que se encarama a las seis décadas y que se dedicaba al tráfico de drogas de primera calidad [...]" (La Cuarta, 32-XI-98, p. 3, c. 5).

Pirulín (de pirulo, V.) m. dimin. neo. Pirulo 3. Ú. m. c. pl. "Por su parte, el francés Jeanpierre, de 18 pirulines, se refirió al estilo de juego que tiene [...]" (La Cuarta, 7-XI-98, p. 9, c. 4).

*Pirulo, la (de pirúl 'pedazo de masa frita o de madera en forma cilíndrica' del mapuche pirull 'huso' y éste del quechua piruru 'disco cilíndrico del huso'; cf. Lenz DE pp. 608 y 609, donde también justifica la analogía de pirul con pirulo 'elegante') adj. fam. Elegante, distinguido. "Aunque estos concertistas visten pirulo traje, son lo menos empaquetados que hay [...]" (La Cuarta, 23-XI-98, p. 29, c. 3). || 2. adj. y s. Dep. Relativo al Club Deportivo de la Universidad Católica. "Jaime Pizarro reaparece en el elenco pirulo, que pretende borrar sus últimas actuaciones, bastante charchas [...]" (La Cuarta, 29-XI-98, p. 11, c. 1). || 3. m. vulg. Año de edad. "Moisés Zamorano, un abuelito de 86 pirulos que es como tonto para correr y que quiere ser campeón del mundo" (La Cuarta, 23-XI-98, p. 20, c. 1). Var.: pirulín. || 4. adj. vulg. Adinerado, relativo o perteneciente al estrato social alto "Además se cachó que acato los pingüinitos son medio porros en matemáticas y que es mejor la educación de los colegios pirulos que en los públicos [...]" (La Cuarta, 9-XII-98, p. 6, cc. 1 y 2).

Pitearse (tal vez de pitear, variante de pitar 'fumar cigarrillo', pitarse una cosa 'hurtar', según Lenz del guaraní pité 'chupar' o pety 'tabaco'; cf. Lenz DE p. 617) prnl. vulg. Estropear, echar a perder, deteriorar. "Justamente, le estoy telefoneando a nombre de todos los vecinos de la población Pincoya 1, onda Huechuraba, para contarle que los compadres de EMOS se pitearon un tremendo condoro" (La Cuarta, 24-XI-98, p. 7, c. 4). 
* Pololear (de pololo, la , V.) tr. fig. fam. fest. Tratar de seducir o convencer, como cuando se corteja a alguien. "Los cabros institutanos (de blanco) se fletaron en la final al San Benito. Tres de ellos son pololeados por la 'U', que los quiere tener de potrillitos" (La Cuarta, 23-XI-98, p. 11, cc. 1 y 2 ).

*Pololo, la (del mapuche púldu, púl-lu 'mosca, moscardón'; cf. Lenz DE pp. 622 y 623 y Prieto Indigen. p. 214) $\mathrm{m}$ y f. fam. Persona con la que se mantiene una relación amorosa informal. "Así la cabra se mete en una espiral de adicciones y decide mandarse cambiar. Empieza el drama, porque el pololo no le aguanta la pará. Bárbara se echa el pollo con la mala pata de que justo tiene un accidente" (La Cuarta, 20-V-04, p. 19, cc. 2 y 3 ). "No dice si el perforador estudia o trabaja, pero si está en al universidad le apuesto que tiene una polola oficial al alcance de la mano y otras cuestiones todos los días" (La Cuarta, 22-VI-04, p. 23, c. 4).

*Poroto, ta (del quechua purútu 'habichuela'; cf. Lenz DE pp. 627-633, Prieto Indigen. p. 215 y Prieto Quechui. p. 170) m. y f. fig. fam. Niño o niña. "Las 'tías' Pintapinta entretienen con juegos, lápices de colores y cualquier amor a una de las porotas que asiste periódicamente al Hospital Roberto del Río para mejorarse rápido y salir a chacotear con los amigos" (La Cuarta, 7-XI-98, p. 24, c. 1). Sin.: chapulín. || 2. m. vulg. Aporte, contribución. "En buena hora les llegó a las jefas de hogar de San Joaquín la inauguración de los centros abiertos 'El Pinar' y 'Bello Horizonte', pues gracias al poroto de la Fundación Integra, ya no tendrán que dejar a sus cabros con sus hermanos mayores o con la vecina [...]" (La Cuarta, 6-XI-98, p. 6, c. 2). \| ganarse los porotos loc. prnl. fig. fam. fest. Ganarse el sustento, trabajar o buscar medios para mantenerse. "Soy una lola de 20 años recién cumplidos, soltera, vivo con mis papás, quienes me pagan los estudios en un instituto, para que después me gane los porotos" (La Cuarta, 29-XI-98, p. 27, c. 4).

Porotazo (de poroto, V.) m. aum. Poroto 2. "Descubrieron que compuesto usado en experimentos puede causar cáncer y malformaciones / Cerebros chilenos lanzan alerta mundial por 'clonación mutante' [...] El porotazo logrado en nuestro país fue replicado en Tokyo [...]"( La Cuarta, 20-V04 , p. 6, c. 2-5).

*Poto (del mapuche homónimo c. i. s.; cf. Lenz DE p. 635) m. fam. Trasero, nalgas. "El galán tiene serios conflictos con el jabón y lo han pillado en reiteradas ocasiones con un concentrado aroma a ala... o incluso a rodilla (entre pata y poto)" (La Cuarta, 18-V-04, p. 21, c. 1). "En la calle anda 
mirándoles el poto y las pechugas a las mujeres y se le pone la carne de gallina [...]" (La Cuarta, 19-V-04, p. 23, c. 4). Obs.: DRAE registra forma semejante pero con otro origen y acepción.

Poruñazo (de poruña 'especie de cucharón en forma de media caña, de un pedazo de cuerno de vacuno partido, usado en los lavaderos de oro', del quechua puruña 'fuente de barro para los usos de la cocina', de ahí, también, poruñear 'engañar, estafar a otro con noticias o muestras falsas'; cf. Lenz DE p. 634). m. vulg. aum. Golpe, atraco, robo. "El último poruñazo se lo pegó el sábado 5 de junio, cuando -nadie sabe cómo- abrió el Grand Nomade 2004 que Claudia Juri había estacionado con alarma activada en el McDonald's al lado del Parque Arauco" ( $L a$ Cuarta, 16-VI-04, p. 3, cc.3-4).

Puchito (de pucho, V.) m. dimin. aprec. fam. Pucho. "Pidieron un puchito y los agarraron a balazos al tirante / Crimen por cigarro" (La Cuarta, 29-XI-98, p. 1, cc. 2 y 3 ).

*Pucho (de pucho 'colilla de cigarro' y éste del quechua puchu 'lo que sobra, residuo', de ahí también al lunfardo; cf. Lenz DE p. 639 y 640, BDL. p. 61 y Cammarota Lunfard. p. 170 y Prieto Quechui. p. 171) m. fam. Cigarrillo. "Estos últimos se acercaron a los primeros, pidiéndoles un cigarrillo de mala forma, lo que generalmente corresponde al inició de un asalto callejero, o sea, un vulgar cogoteo [...] Total que en lugar de ponerse con un pucho, los tipos desenfundaron armas de fuego y dispararon varias veces" (La Cuarta, 29-XI-98, p. 3, cc. 5 y 6). Var.: puchito. $\|$ pucho lacio loc. adj. fig. vulg. fest. Impotente, dícese del varón que no puede mantener la erección de su miembro viril. "En asalto a farmacia: Puchos lacios les harán chupete / Roban cinco mil dosis de viagra" ( $L a$ Cuarta, 23-XI-98, p. 1, cc. 1-3).

\section{Q}

Quique, hecho un (quique 'especie de huron o comadreja, galictis vittata', del mapuche quiqui c. i. s.; cf. Lenz DE p. 673) loc. part. fig. fam. Muy enfadado, iracundo, furioso. "Quién puso el tema en el tapete es el técnico de los itálicos, el 'Cacho' Malbernat, que está hecho un quique con el asunto [...] explicó que su molestia pasa 'por los horarios en que se disputarán los partidos [...]'” (La Cuarta, 10-XII-98, p. 11, cc. 2 y 3). 
*Quisca (del quechua kiska 'espina, púa del espino y otros vegetales', de ahí al coa homónimo 'cuchillo'; cf. Lenz DE p. 675, Prieto Indigen. p. 217, Prieto Quechui. p. 178 y Vicuña Coa p. 127) f. fig. vulg. Cuchilla, arma blanca cortopunzante. "Voy a empezar por el final: No haga nada, salvo tratar que no lo pille el guatón que debe llamarse Pedro Navaja y parece que es como tonto para la quisca" (La Cuarta, 21-XI-98, p. 23, c. 4). Obs.: cf. Rivera 1965, p. 352 y 353.

\section{$\mathbf{R}$}

Ruca (del mapuche homónimo 'casa, rancho'; cf. Lenz DE p. 688) f. neo. Sede del Club Deportivo Colo Colo. "El capitán de Colo Colo llegó acompañado del técnico Jaime Pizarro, los integrantes del plantel y el síndico Patricio Jamarne, hasta el hall central de la ruca del monumental [...]"(La Cuarta 22-VI-04, p. 9, c. 1).

\section{$\mathbf{S}$}

Sohua (metátesis regresiva de huaso 'campesino chileno', de origen incierto, tal vez quechua o antillano; cf. Lenz DE pp. 384-386 y Prieto Indigen. pp. 191 y 192) adj, y s. Relativo al Club Deportivo Rangers de Talca y p. ext. cualquier equipo del sur del país. "Añadió el 'Cacho' Malbernat que durante la semana le pondrán firmeza el hombro para llegar como relojito a la mocha con los sohuas de Rangers [...]" (La Cuarta, 24-XI98 , p. 13, c. 6). Var.: sohuita.

Sohuita (de sohua, V.) m. dimin. aprec. Dep. Sohua. "Una angustiosa pero justa victoria logró el 'Chago' ante los 'sohuitas' melipillanos. Los tres puntos fueron los boletos a la 'liguilla del terrror' " (La Cuarta, 29-XI98 , p. 14 , c. 2 ). 


\section{$\mathbf{T}$}

*Taita (del quechua táyta 'padre, progenitor'; Lenz DE p. 701 y 702 y Prieto Indigen. pp. 218 y 219) m. inf. Padre. “Mis tíos compiten y mi papá lo hizo en el Rally, así ambos venimos de una familia rica en tradición automovilística'. El caso de "Joselito" Riffo es muy similar, ya que su taita le inyectó octanaje en la sangre [...]" (La Cuarta, 18-V-04, p. 11, cc. 4-5). Obs.: aparece en el DRAE, s. v. taita, con la misma acepción, pero no se consigna etimología indígena.

Tata (síncope de taita, V.) m. inf. Anciano. “[...] parloteó el edil, quien asegura conocer de cerca la realidad de los tatas, y que vive solo con su mamita de 75 otoños" (La Cuarta, 23-XI-98, p. 32, c. 1). Var.: tatita.

Tatita (de tata, V.) m. dimin. aprec. inf. Tata. "Los cabros de San Ramón ya se preparan para celebrar 1999 como el Año Internacional del Adulto Mayor. De hecho, la muni local organizó una caminata de tatitas a todo cachete el sábado [...]" (La Cuarta, 23-XI-98, p. 32, c. 1).

*Tincada (de tincar, V.) f. fig. fam. Corazonada, presentimiento. "Favorito (7) Pituco [caballo de carreras]: Es buena tincada para salir cobrando" (La Cuarta, 7-XI-98, p. 18, c. 4).

*Tincar (del quechua t’inkay; cf. DRAE s. v. y Prieto Quechui. p. 181) intr. fig. fam. Intuir, darle a alguien una corazonada o presentimiento. "Donde hay uno, hay otro y me tinca que de repente saldrá un fulano bueno para los cuetes y que le cascará con tutti" (La Cuarta, 23-XI-98, p. 31, c. 4).

Tongua (metátesis regresiva de guatón, V.) m. y adj. vulg. y juv. fest. despec. Guatón 1. "Ricitos de oro hace un buen rato que algo se traía entre manos y no halló nada mejor que contar la pulenta en el estelar del tongua Schiappacasse [...]" (La Cuarta 16-VI-04, p. 18, c. 1).

Tuna, como (tuna V. tunazo) loc. adv. fam. pond. En excelente forma o condición física. "Nació en Osorno y, para mantenerse como tuna, realiza nada menos que 400 abdominales diarios, 200 en la mañana y 200 por la noche" (La Cuarta, 23-XI-98, p. 20, c. 1).

Tunazo (de tuna 'fruto de la cetácea opuntia vulgaris', origen incierto, tal vez haitiano; cf. Lenz DE pp. 749 y 750) m. aum. vulg. y jerg. delict. Balazo. "Capturados dos delincuentes en medio de nutrida balacera / 
En medio de un cinematográfico intercambio de tunazos, funcionarios de Carabineros aprehendieron a dos malandrines [...]" (La Cuarta, 29XI-98, p. 3, c. 3).

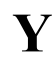

Yayita (de yaya, variante de nána 'dolencia o lastimadura pequeña', del quechua nany 'dolor, enfermedad'; cf. Lenz DE p. 520) f. dimin. aprec. fam. Falencia, defecto o ilegalidad que causa perjuicio. "El informe final [...] dejó al descubierto una serie de yayitas de dicha empresa en cuanto a honorarios, comisiones de servicio al extranjero, remuneraciones y viáticos" (La Cuarta, 24-XI-98, p. 5, c. 3).

\section{CONCLUSIONES}

Los principales hallazgos de nuestro estudio pueden sintetizarse como sigue:

1. El número de unidades léxicas que se ajustan a nuestra definición de neologismo estilístico de base indígena, documentados en la muestra analizada asciende a 132.

2. En total, los 132 neologismos estilísticos de base indígena registraron 530 ocurrencias en una masa léxica estimada de 375.000 palabras. Este cálculo se realizó según una estimación de 1.000 palabras por cada una de las 375 páginas correspondientes a los 15 ejemplares del diario $L a$ Cuarta. Dicho de otra manera, la densidad del elemento léxico de carácter estilístico y origen extranjero en la masa léxica antes señalada representa, aproximadamente, el $0,14 \%$ del total de la misma.

3. La influencia de lenguas indígenas en el registro festivo de La Cuarta se manifestó, principalmente, a través de voces de origen quechua (60) y mapuche (48). Le siguen a gran distancia el náhuatl (5), guaraní (4), aimará (3) y rapanui (1). También se registraron otras voces y locuciones 
de origen incierto (11), pero que -probablemente- sean de origen indígena.

4. La mayoría de los neologismos estilísticos de origen indígena son préstamos que manifiestan adaptación semántica, es decir, se verifica en ellos algún proceso de cambio semántico de tipo metafórico. Por otra parte, existe una clara predisposición de estas unidades léxicas a formar familias de derivados y establecer relaciones de sinonimia, si bien esta última tendencia no es tan marcada como en el caso de la generación de formas derivadas. Asimismo, se verificó una notable participación de estas voces o sus derivados en unidades fraseológicas. Sin embargo, la presencia de parasintéticos y, aún más, de compuestos con base indígena es muy inferior. 


\section{REFERENCIAS BIBLIOGRÁFICAS}

Cammarota, Federico. 1970. Vocabulario familiar y del lunfardo. Buenos Aires: A. Peña Lillo Editor.

CASARES, Julio. 1950. Introducción a la lexicografía moderna. Madrid: Revista de Filología Española, Anejo LII.

Gobello, José y Luciano Payet. 1959. Breve diccionario lunfardo. Buenos Aires: A. Peña Lillo Editor.

Guiraud, Pierre. 1965. La semántica. México: Fondo de Cultura Económica.

Kany, Charles. 1962. Semántica hispanoamericana. Madrid: Aguilar.

LiRA, Pedro. 1973. Estudios sobre vocabulario. Santiago: Editorial Andrés Bello.

Lastra, Yolanda. 1992. Sociolingüiśtica para hispanoamericanos. Una introducción. México: El Colegio de México.

Lenz, Rodolfo. 1905-1910. Diccionario etimológico de las voces chilenas derivadas de lenguas indigenas americanas. Santiago: Imprenta Cervantes (reedición dirigida por Mario Ferreccio).

Morales Pettorino, Félix. 1984. Diccionario ejemplificado de chilenismos y de otros usos diferenciales del español de Chile (4 tomos). Valparaíso: Universidad de Playa Ancha de Ciencias de la Educación.

Oroz, Rodolfo. 1937-1938. El elemento afectivo en el lenguaje chileno. AFFE T. II, Cuaderno $\mathrm{N}^{\circ} 1: 36-57$. ria.

Prieto, Luis. 1979. Indigenismos léxicos en las publicaciones periodísticas de Santiago de Chile. Boletín de Filología de la Universidad de Chile XXX: 105-240.

1982-1983. El elemento italiano an las publicaciones periodísticas de Santiago de Chile. Boletín de Filología de la Universidad de Chile XXXII: 113-163.

1992. Galicismos léxicos en la prensa de Santiago de Chile. Boletín de Filología de la Universidad de Chile XXXIII: 79-249.

1993-1994. Italianismos léxicos en la prensa de Santiago de Chile (1976-1993). Boletín de Filología de la Universidad de Chile XXXIV: 271-459.

2002-2003. Germanismos en el léxico de la prensa de Santiago de Chile. Boletín de Filología de la Universidad de Chile XXXIX: 141-267.

2004-2005. Afronegrismos en el léxico de la prensa de Santiago de Chile. Boletín de Filología de la Universidad de Chile XL: 85-135. 
2006. Quechuismos en la prensa de Santiago de Chile. Boletín de Filología de la Universidad de Chile XLI: 97-196.

2007. Voces de origen japonés en el léxico de la prensa de Santiago de Chile. Boletín de Filología de la Universidad de Chile XLII: 157-317.

Rabanales, Ambrosio. 1953. Introducción al estudio del español de Chile. Determinación del concepto de chilenismo. Universidad de Chile: Anejo $N^{o} 1$ del Boletín de Filología.

1958. Recursos lingüísticos, en el español de Chile, de expresión de la afectividad. Boletín de Filología de la Universidad de Chile X: 129-155.

Real Academia Española. 2001. Diccionario de la lengua española. $22^{\mathrm{a}}$ ed. Madrid: Espasa Calpe.

Rivera, Hugo. 1965. Glosario de la novela "Chicago chico" de Armando Méndez Carrasco y otros autores. Boletín de Filología de la Universidad de Chile XVII: 281-361.

Román, Manuel Antonio. 1901-1918. Diccionario de chilenismos y otras locuciones viciosas (5 tomos). Santiago: Imprenta de San José.

Rotaexte, Karmele. 1990. Sociolingüistica. Madrid: Síntesis.

San Martín, Abelardo. 2000-2001. Procedimientos de creación léxica en el registro festivo del diario chileno La Cuarta. Boletín de Filología de la Universidad de Chile XXXVIII: 211-251.

VICUÑA, Julio. 1910. Coa, jerga de los delincuentes chilenos (Estudio y vocabulario). Santiago: Imprenta Universitaria.

WAGNER, MAX LEOPOLD. 1950. El sufijo hispanoamericano - eco para denotar defectos físicos y morales. Nueva Revista de Filología Hispánica 4, № 2: 105-114. 